DEMOGRAPHIC RESEARCH

VOLUME 41, ARTICLE 33, PAGES 953-1006

PUBLISHED 11 OCTOBER 2019

https://www.demographic-research.org/Volumes/Vol41/33/

DOI: 10.4054/DemRes.2019.41.33

Research Material

Internal migration in the United States:

A comprehensive comparative assessment of the Consumer Credit Panel

Jack DeWaard

Janna Johnson

Stephan Whitaker

(C) 2019 Jack DeWaard, Janna Johnson \& Stephan Whitaker.

This open-access work is published under the terms of the Creative Commons Attribution 3.0 Germany (CC BY 3.0 DE), which permits use, reproduction, and distribution in any medium, provided the original author(s) and source are given credit.

See https://creativecommons.org/licenses/by/3.0/de/legalcode. 


\section{Contents}

1 Introduction $\quad 954$

$2 \quad$ Problems with migration data 955

3 Introducing the Consumer Credit Panel (CCP) 957

$4 \quad$ Overview of empirical approach 959

4.1 Cross-sectional analysis $\quad 959$

$\begin{array}{lll}4.1 .1 & \text { Data } & 959\end{array}$

4.1.2 Measures $\quad 962$

4.1.3 Results 963

4.2 Longitudinal analysis 972

4.2.1 Data 972

4.2.2 Measures 975

4.2.3 Results 976

5 Discussion $\quad 985$

6 Acknowledgments $\quad 987$

$\begin{array}{ll}\text { References } & 988\end{array}$

$\begin{array}{ll}\text { Appendix } & 995\end{array}$ 


\title{
Internal migration in the United States: A comprehensive comparative assessment of the Consumer Credit Panel
}

\author{
Jack DeWaard ${ }^{1}$ \\ Janna Johnson ${ }^{2}$ \\ Stephan Whitaker ${ }^{3}$
}

\begin{abstract}
BACKGROUND

We introduce and provide the first comprehensive comparative assessment of the Federal Reserve Bank of New York/Equifax Consumer Credit Panel (CCP) as a valuable and underutilized dataset for studying internal migration within the United States. Relative to other data sources on US internal migration, the CCP permits highly detailed cross-sectional and longitudinal analyses of migration, both temporally and geographically.
\end{abstract}

\section{OBJECTIVE}

We seek to demonstrate the comparative utility and some of the unique advantages of the CCP relative to other data sources on US internal migration.

\section{METHODS}

We compare cross-sectional and longitudinal estimates of migration from the CCP to similar estimates derived from the American Community Survey, the Current Population Survey, Internal Revenue Service data, the National Longitudinal Survey of Youth, the Panel Study of Income Dynamics, and the Survey of Income and Program Participation.

\section{RESULTS}

Our results firmly establish the comparative utility and clearly illustrate some of the unique advantages of the CCP relative to other data sources on US internal migration.

\section{CONCLUSIONS}

We conclude by identifying some profitable directions for future research on US internal migration using the $\mathrm{CCP}$, as well as reminding readers of the strengths and limitations of these data.

\footnotetext{
${ }^{1}$ University of Minnesota Twin Cities, Minneapolis, USA. Email: jdewaard@umn.edu.

${ }^{2}$ University of Minnesota Twin Cities, Minneapolis, USA.

${ }^{3}$ Federal Reserve Bank of Cleveland, Cleveland, OH, USA.
} 


\section{CONTRIBUTION}

We provide an introduction to the $\mathrm{CCP}$ as a comprehensive comparative point of reference to stimulate future research on US internal migration using these data. More broadly, this paper contributes to research on the use of nontraditional data sources to study migration given well-documented problems with the availability, quality, and comparability of migration data from traditional sources.

\section{Introduction}

Human migration is an important demographic, economic, environmental, geopolitical, and sociocultural process (Black et al. 2011; Bodvarsson and Van den Berg 2013; Brettell and Hollifield 2015; Castles, de Haas, and Miller 2014; Grecequet et al. 2017; Massey et al. 1998; Merli et al. 2009; Nawrotzki and DeWaard 2018; White 2016). It is therefore concerning that migration data have been and continue to be plagued by significant problems of availability, quality, and comparability. While these problems are pronounced for data on international migration (Abel and Sander 2014; DeWaard et al. 2017; Levine, Hill, and Warren 1985; Poulain, Perrin, and Singleton 2006; Raymer et al. 2013; Willekens et al. 2016), data on internal migration are not immune (Bell et al. 2002, 2015a, 2015b).

With respect to the aim of this paper, this lack of immunity applies to data on internal migration in the United States (Isserman, Plane, and McMillen 1982; Kaplan and Schulhofer-Wohl 2012; Long 1988; Molloy, Smith, and Wozniak 2011) and motivates our work to introduce and provide the first comprehensive comparative assessment of the Federal Reserve Bank of New York/Equifax Consumer Credit Panel (CCP) to demonstrate the utility and some of the unique advantages of these data (Lee and van der Klaauw 2010; Whitaker 2018). We begin by introducing the CCP and describing two problems that they resolve better than other data sources on US internal migration. We then compare cross-sectional estimates of migration from the CCP to similar estimates derived from the American Community Survey (ACS), the Current Population Survey (CPS), and migration data from the Internal Revenue Service (IRS). This is followed by comparing longitudinal estimates of migration from the CCP to similar estimates derived from the National Longitudinal Survey of Youth (NLSY 1979 and 1997), the Panel Study of Income Dynamics (PSID), and the Survey of Income and Program Participation (SIPP 2004 and 2008).

Our results firmly establish the comparative utility and clearly illustrate some of the unique advantages of the CCP relative to other data sources on US internal migration, thereby warranting greater use of these data in future research on internal 
migration in the United States. More broadly, whether focused on the United States or not, our work adds to the growing body of research on the use of nontraditional data sources, such as social media data (Cesare et al. 2018), to study migration given welldocumented problems with the availability, quality, and comparability of migration data from traditional sources like censuses and surveys.

\section{Problems with migration data}

At a basic level, migration is one of three components of population change; however, extensive literatures also detail the economic, environmental, geopolitical, and sociocultural causes, characteristics, and consequences of migration (Ali and Hartmann 2015; Bodvarsson and Van den Berg 2013; Black et al. 2011; Brettell and Hollifield 2015; Castles et al. 2014; Hunter, Luna, and Norton 2015; Massey et al. 1998; Massey and España 1987; Massey, Pren, and Durand 2016; National Academies of Sciences, Engineering, and Medicine 2017; White 2016). Given the breadth and depth of past and current efforts to study migration, as well as policy efforts to monitor and manage migration (IOM 2018), it is therefore concerning that migration data are notoriously poor and suffer from well-documented problems of availability, quality, and comparability.

These problems are particularly severe for data on international migration (Abel and Sander 2014; Levine, Hill, and Warren 1985; Poulain, Perrin, and Singleton 2006; Raymer et al. 2013; Willekens et al. 2016). Bracketing the issue of whether data on international migration are collected at all, the quality and comparability of migration data are problematic for at least three reasons. First, due to both the different underlying definitions and data collection systems used, information is not necessarily collected on the same phenomenon. For example, in some cases, data on migrations (i.e., transitions or events) are collected, while, in others, data on migrants (i.e., persons who have changed their residential status) are collected. Second, if one or more are employed at all, different timing criteria (one-year, a few months, etc.) are used to identify and therefore count migrations and migrants. Third, there are substantial differences with respect to coverage and undercount, which is an increasingly important consideration in light of whether and how countries track and ultimately respond to flows of asylum seekers and refugees (Abel 2018; Long 2015). As a result, bracketing several recent sets of harmonized estimates of international migration among European countries (e.g., see Raymer et al. 2013), publicly available data on international migration (e.g., from the World Bank and the United Nations), and estimates derived from them (e.g., see Abel and Sander 2014) are of differing quality and are not necessarily comparable across 
countries. The same is true for cross-national comparisons of internal migration data and estimates (Bell et al. 2002, 2015a, 2015b).

Even if the focus is restricted to internal migration in a single country like the United States, which is the focus of this paper, and to one data source, two key problems remain (Isserman, Plane, and McMillen 1982; Kaplan and Schulhofer-Wohl 2012; Long 1988; Molloy, Smith, and Wozniak 2011). The first problem is that there is usually a tradeoff between temporal and geographic specificity. With respect to the former, more frequent measurements of migration permit seeing migration for what it is - namely, a demographic event. However, more frequent measurements of migration come at the expense of data collected at finer spatial scales (counties, census tracts and blocks, etc.). Further complicating this picture is that many data sources commonly used to study US internal migration (e.g., the CPS and the PSID) are surveys with small sample sizes. This raises serious concerns about the accuracy of estimates of migration, especially at finer spatial scales, as well as privacy concerns (Abowd 2018; Ruggles 2018).

The second problem of sample attrition is unique to longitudinal migration data. To provide a concrete example, while the PSID took precautions to ensure high rates of follow-up in each successive wave after the start of the survey in 1968 (Hill 1992), "attrition in the PSID has been substantial" (Fitzgerald 2011: 2; see also Fitzgerald, Gottschalk, and Moffitt 1998; Lillard and Panis 1994). The same is true for other longitudinal surveys like the SIPP (Zabel 1998). Not surprisingly, numerous studies have been conducted to ensure that the PSID has remained nationally representative (Fitzgerald, Gottschalk, and Moffitt 1998; Hill 1992; Morgan 1979). However, these efforts and findings notwithstanding, high attrition in longitudinal surveys like the PSID and SIPP further calls into question the accuracy of estimates of migration, especially over longer time spans and at finer spatial scales.

As a result of the two problems discussed above, what we know and do not know about internal migration in the United States, both temporally and geographically, is a mixed bag that reflects substantial differences in the logic, implementation, and shortcomings of existing approaches and resulting datasets (Isserman, Plane, and McMillen 1982; Kaplan and Schulhofer-Wohl 2012; Long 1988; Molloy, Smith, and Wozniak 2011). And while there is always some slippage between the ideal and what is feasible in practice, the overarching aim of this paper is to call attention to other valuable and underutilized data sources - specifically, the CCP - that better resolve the two problems discussed above. 


\section{Introducing the Consumer Credit Panel (CCP)}

As described in detail by Lee and van der Klaauw (2010) and Whitaker (2018), data in the CCP are drawn from a list of credit histories of 240 million US adults maintained by Equifax, which is one of three national credit-reporting agencies (NCRAs). Firms that extend credit to consumers provide monthly reports to NCRAs containing the addresses of borrowers and information on debt-financed consumption activities, including outstanding balances, payments, delinquencies, and more. Credit records contain an address that the NCRA has determined is most likely to be the borrower's current mailing address. Changes in these credit record addresses can be used to study migration.

Each month, Equifax feeds all recently reported addresses through a proprietary algorithm that determines whether the address associated with the file should be updated. The algorithm retains the existing address in the record until recently reported addresses provide sufficient evidence that the borrower has moved by agreeing on a new location. Reports from creditors that are considered the most reliable are given the greatest weight. For example, mortgage lenders are very likely to have an accurate address because the address identifies their loan collateral. In instances where people have statements addressed to multiple locations, the algorithm selects the address based on the most important and number of accounts. Equifax reports the census block containing the mailing address for each observation in the CCP. ${ }^{4}$ Approximately $6 \%$ of addresses in the CCP are post office boxes, which are geocoded to the location of the post office. Provided that post office boxes are in the same area (e.g., state and county), as a borrower's residence, and that the borrower redirects their mail when they move, this should not bias estimates of migration. If a borrower makes a local move without changing their post office box, this move would not be observed in the CCP.

The CCP sample is drawn from the complete set of Equifax records. Each quarter, a subset of records is extracted containing every borrower for whom the last two digits of their social security number matches one of five preselected random two digit numbers. ${ }^{5}$ The same five random numbers are used each quarter. Because it is extremely rare for an individual's social security number to change, the same individuals appear in each quarterly sample, thus building their individual panel over

\footnotetext{
${ }^{4}$ For privacy and security reasons, Equifax anonymizes the data before sending it to researchers. Names are removed. Social security numbers are replaced with a different unique identification number that can be used to link individuals across quarters. The data contain the census block of each borrower's current address but not the actual street address.

${ }^{5}$ The last four digits of an individual's social security number are determined by the order of arrival of applications for social security numbers in each state. Numbers are assigned from 0001 to 9999 and then resume at 0001 . This is no mechanism for individuals to select a particular number (and no motivation save numerology). They are effectively random.
} 
time. When a first-time borrower appears with a matching social security number, they enter the sample. Individuals can exit the sample by passing seven years with no credit activity, emigrating from the United States, or dying. According to Lee and van der Klaauw (2010: 3), the end result of these procedures is "a $5 \%$ random sample that is representative of all individuals in the US who have a credit history and whose credit file includes the individual's social security number."

Presently, more than 100 papers, including working papers, have been published using the CCP. ${ }^{6}$ Consumer debt is the most commonly studied topic; however, several papers have used the CCP to study internal migration and mobility. For example, Molloy and Shan (2013) showed that experiencing foreclosure increases the risk of moving, but not to less desirable neighborhoods. In contrast, Ding, Hwang, and Divringi (2016: 38; see also Hwang 2018) found that those with low credit scores, or 'vulnerable residents,' are not more likely than those with high credit scores to move from gentrifying neighborhoods; however, those who do leave tend to move to less desirable neighborhoods. Both Molloy and Shan (2013) and Ding, Hwang, and Divringi (2016) operationalized neighborhoods as census tracts, thus highlighting an important strength of the CCP, which is that borrowers in individual census blocks can be aggregated up to any desired spatial scale (census tracts, municipalities, counties, etc.). Additionally, and importantly, the CCP are available on a quarterly basis. ${ }^{7}$ This means that the CCP data can be recoded to study migration at and over different time intervals (semi-annually, annually, etc.). Molloy and Shan (2013) and Ding, Hwang, and Divringi (2016), for example, used the CCP to study annual migration, and we follow their lead in this paper.

Another strength of the CCP, especially relative to other data sources like the CPS and PSID, is its very large sample size of about 10 million borrowers per year. This helps to reduce the tradeoff between temporal and geographic specificity, discussed in the previous section. Also, because the data in the CCP are drawn from the set of all US adults with a credit report and social security number, problems of follow-up and attrition are comparatively less severe.

There are several weaknesses of the CCP. First, according to the Consumer Financial Protection Bureau, about $10-11 \%$ of US adults lack a credit history with an NCRA (Brevoort, Grimm, and Kambara 2016). These numbers are higher (about 30\%) and lower (about 4\%) in low- and high-income neighborhoods respectively. The CCP is therefore a sample of relatively older and more financially established adults, and it is not appropriate for more targeted studies of younger and/or financially disadvantaged persons. Second, the CCP is limited with respect to observables. While the CCP

\footnotetext{
${ }^{6}$ See https://www.newyorkfed.org/microeconomics/hhdc/background.html.

${ }^{7}$ While the Federal Reserve Bank of New York negotiated access to the CCP from Equifax on a quarterly basis, it is possible to negotiate other baseline time intervals (monthly, weekly, etc.).
} 
contains data on age and other information provided in a credit report, in explanatory studies, data in the CCP must often be merged with other data sources (e.g., tract level data from the US decennial census) in order to examine the role of additional demographic and other factors. Third, like other data sources, the CCP does not always consistently drop those who die. Finally, the CCP are proprietary and must be purchased or accessed via collaboration with a researcher at an institution that has an existing data agreement.

Whether the strengths of the CCP outweigh its weaknesses is an open empirical question that has received very limited attention in prior studies. For example, in a single footnote, Molloy and Shan (2013: 233) noted that the migration rate in the CCP "is somewhat higher than the CPS;" however, they neither reported their CCP and CPS estimates nor discussed possible reasons for this discrepancy. Ding, Hwang, and Divringi (2016: 41) went one step further and showed that age-specific migration rates in the CCP were "slightly lower than those in the ACS data;" however, they provided estimates for only two years, 2006 and 2013. Accordingly, in what follows, we provide the first comprehensive comparative assessment of the CCP to demonstrate the utility and some of unique advantages of these data for research on US internal migration.

\section{Overview of empirical approach}

The empirical portion of this paper is divided into two main sections. In the first section, we compare cross-sectional estimates of migration from the CCP to similar estimates from the ACS, CPS, and IRS. In the second section, we compare longitudinal estimates of migration from the CCP to estimates from the NLSY 1979 and 1997, the PSID, and SIPP 2004 and 2008. In doing so, we seek to exhaust the datasets that are most commonly used to study US internal migration and, in the process, to provide an important point of reference for current and future research that will be of interest to scholars, policymakers, and practitioners with an interest in US internal migration.

\subsection{Cross-sectional analysis}

\subsubsection{Data}

Earlier, we suggested that some of what is known and unknown about internal migration in the United States reflects differences in the logic, implementation, and shortcomings of existing approaches and resulting datasets (Isserman, Plane, and McMillen 1982; Kaplan and Schulhofer-Wohl 2012; Long 1988; Molloy, Smith, and 
Wozniak 2011). As we show in Table 1, each of the four datasets used in our crosssectional analysis is characterized by a different universe, sample size, time span, and migration information. These differences affect the comparability of the estimates derived from these datasets. The selection criteria provided in the final column of Table 1 thus represent our best attempt to restrict our analysis to the most comparable sets of observations in these four datasets, and we discuss the implications of the remaining differences for our results below.

Following Molloy and Shan (2013) and Ding, Hwang, and Divringi (2016), we focus on annual migration over the past decade or so from 2005 forward at the state, county, and tract levels. Data on state migration are available in all four datasets. Data on county migration are available in the CCP, CPS, and IRS. The ACS does not contain county migration data and, instead, contains migration data for Public Use Microdata Areas of Migration (MIGPUMAs), which are population-based geographic units. ${ }^{8}$ Data on tract migration are only available in the CCP. Our analysis also includes disaggregation by age group, described in the next subsection.

${ }^{8}$ See https://usa.ipums.org/usa-action/variables/MIGPUMA\#description_section. 
Table 1: Descriptions of cross-sectional datasets

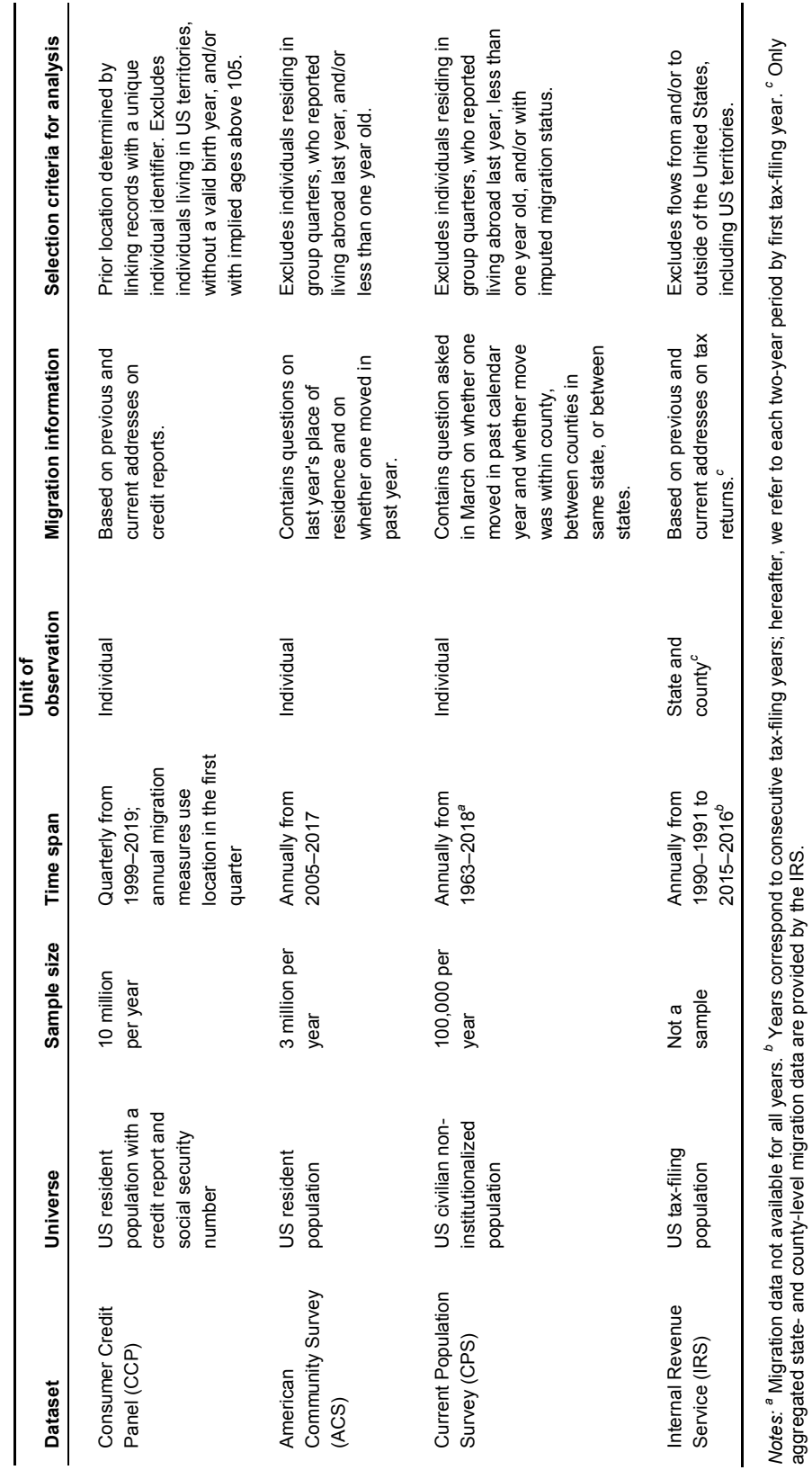




\subsubsection{Measures}

Just as there are many different datasets used to study US internal migration, there are many different ways to measure migration. As the measurement of migration is not the focus of this paper, we follow the lead of Bell et al. (2002, 2015a, 2015b), who have spent the better part of the last two decades establishing and advocating for a set of best measurement practices that tap four dimensions of migration-intensity, distance, connectivity, and effect - in a parsimonious way. Starting with the simplest of these measures, we calculate the Crude Migration Probability $(C M P)$ in each data set as the ratio of the total number of migrants $(M)$ in a given year divided by the total size of the population $(P)$ at the start of the year. We subsequently calculate the $C M P$ for each of three age groups: 'young adults' between the ages of 25 and 29, 'family age adults' between the ages of 30 and 49, and 'older adults' between the ages of 50 and 74 (Johnson, Winkler, and Rogers 2013: 1).

$$
C M P=\frac{M}{P} .
$$

The CMP is a measure of the 'intensity,' or size or magnitude, of migration (Bell et al. 2002: 442), and it ignores the inherently spatial character of migration (Rogers 1975; Roseman 1971). Accordingly, as a measure of the spatial 'connectivity' of migration (Bell et al. 2002: 452), we also calculate the annual Index of Migration Connectivity $\left(I_{M C}\right)$ as follows:

$$
I_{M C}=\frac{\sum_{i \neq j} \sum_{j \neq i} M C_{i j}}{n(n-1)} .
$$

In the numerator of Equation 2, $M C_{i j}=1$ if there is a migration flow from place $i$ to place $j$ of any size greater than zero $\left(M C_{i j}=0\right.$ otherwise). In the denominator, $n$ is the total number places comprising the migration network. The $I_{M C}$ ranges from zero to one and summarizes the proportion of all potential place-to-place migration flows that are not zero, or, in more substantive terms, the degree of spatial saturation in the migration network. ${ }^{9}$

The $I_{M C}$ imposes greater data demands than the $C M P$, and it requires data on place-to-place migration flows. Data on state-to-state migration are available in all four datasets. Data on county-to-county migration are only available in the CCP and IRS, with data on MIGPUMA-to-MIGPUMA migration available in the ACS. Finally, data on tract-to-tract migration are only available in the CCP.

\footnotetext{
${ }^{9}$ For those accustomed to the language of [social] network analysis, $M C_{i j}, n$, and, $I_{M C}$ are referred to as directed edges, nodes, and degree centrality respectively.
} 


\subsubsection{Results}

Estimates of the annual $C M P$ at the state, county, and tract levels are displayed in Figure 1. These estimates and their associated standard errors are also provided in tabular form in Appendix Table A- $1{ }^{10}$ In the way of preliminaries, first, as should be the case within each dataset, the county $C M P$ is higher than the state $C M P$. In the CCP, the tract $C M P$ is also higher than the county $C M P$. Second, the scale of the $y$-axis is consistent with the idea that migration is a relatively rare event. Third, and finally, each of the nine series displayed has mostly trended downward since 2005. This is consistent with past and current research on the so-called "Great American Migration Slowdown" (Frey 2009: 1; see also Cooke 2013; Kaplan and Schulhofer-Wohl 2017; Molloy, Smith, and Wozniak 2011), which may have started to reverse course in the last year or two (Frey 2017).

Excluding 2005 (discussed below), estimates of the CMP from the CCP are consistent with similar estimates from the ACS, CPS, and IRS. The CCP performs particularly well against the ACS, ${ }^{11}$ and less so against the CPS and IRS. Comparably lower estimates of the state and county CMP in the CPS are likely the product of weak follow-up in the CPS (Koerber 2007). The CPS is designed to collect data in a single week; therefore, little effort is made to contact initial nonresponders. In contrast, the ACS attempts to collect data for up to three months after the initial interview date. This difference in follow-up and other survey procedures means that the CPS is less likely to capture migrants. The CPS also suffers from additional challenges that affect its accuracy in measuring migration. Kaplan and Schulhofer-Wohl (2012) showed that a change in the imputation algorithm used by the CPS in the mid-2000s resulted in a steep and artificial drop in migration rates. Per their advice, we have excluded all individuals with imputed migration status from our CPS estimates.

The IRS data suffer from a different set of problems. One problem stems from the fact that tax returns in consecutive years much be matched in order to identify migrant and nonmigrant returns (roughly equivalent to households) and associated exemptions (roughly equivalent to individuals), a process that is seldom perfect because tax returns are not always filed or filed on time (Gross 2005; Johnson, Bland, and Coleman 2008; Pierce 2015). A second problem is that, starting in 2011, the responsibility for processing these data shifted from the US Census Bureau to the IRS. Importantly, the IRS implemented different data processing, including matching, procedures (Pierce 2015), which may help to explain changes in the state and county CMP after 2011.

\footnotetext{
${ }^{10}$ Only aggregated state- and county-level migration data are provided by the IRS. Accordingly, Appendix Table A- 1 contains estimates of the CMP and associated standard errors from the CCP, ACS, and CPS.

${ }^{11}$ Recall that the ACS contains migration data for MIGPUMAs, not counties, which tend to be larger in size than counties.
} 
Figure 1: Annual crude migration probability of US internal migration at state, county, and tract levels since 2005 in Consumer Credit Panel, American Community Survey, Current Population Survey, and Internal Revenue Service data

Panel A. State
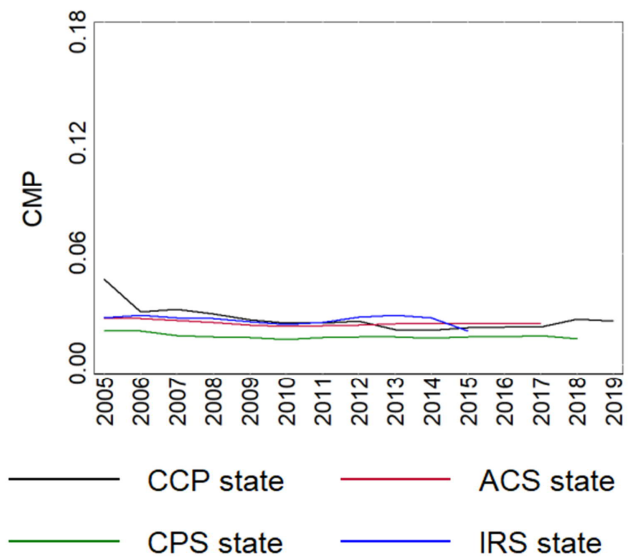

\section{Panel B. County}

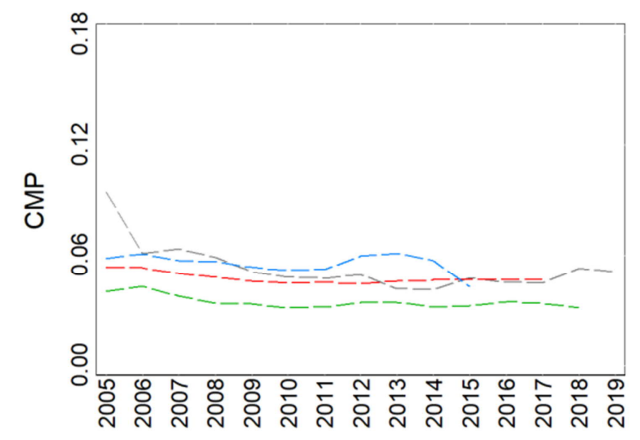

$$
\begin{aligned}
& --- \text { CCP county }--- \text { ACS MIGPUMA } \\
& --- \text { CPS county }--- \text { IRS county }
\end{aligned}
$$


Figure 1: (Continued)

\section{Panel C. Tract}

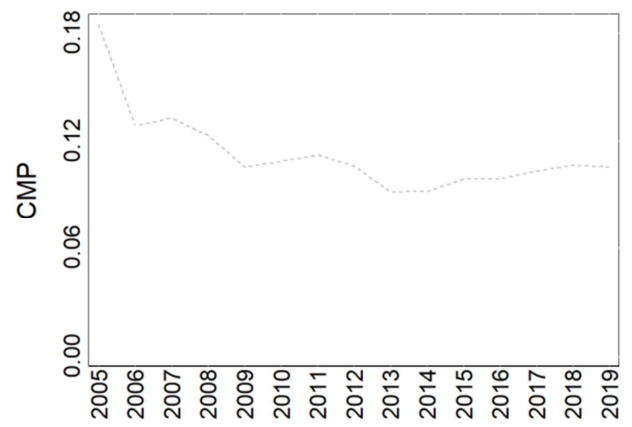

CCP tract

Notes: Selection criteria for analysis provided in Table 1. CMP = Crude Migration Probability; CCP = Consumer Credit Panel; ACS = American Community Survey; $\mathrm{CPS}=$ Current Population Survey; IRS = Internal Revenue Service; MIGPUMA = Public Use Microdata Area for Migration. ACS and CPS estimates are weighted.

Regarding the 2005 estimates of the CMP from the CCP, as well as the pre-2005 estimates (see Appendix Figure A-1), these are noticeable departures from the rest of their respective series from 2006 forward. During this period, Equifax sought to improve the process that it uses to identify borrowers' current mailing addresses from among the many addresses that are reported by their creditors. With each change in the underlying algorithm, there is a corresponding change in the share of records for which the census block (or tract, county, or state) does not match the census block from the same quarter one year before. One of the largest corrections occurred in 2004. These corrections became smaller and less frequent thereafter, which may help to explain the pronounced spike in the CMP from the CCP in 2005. Similar patterns (not shown) are observed for all age groups, regions, debt levels, and credit scores.

The above limitation notwithstanding, a key takeaway from Figure 1 is that estimates of the $C M P$ from the CCP are generally consistent with similar estimates from the other three data sources. Regarding the increase in the state-, county-, and tract-level CCP estimates after 2017, this is consistent with Frey's (2017) suggestion that the United States might be on the cusp of a revival of prerecession migration. Another key takeaway from Figure 1 is that, bracketing the close correspondence between the CCP and ACS estimates, only the CCP permits further examination of annual tract-level migration. Excluding 2005, an average of $10.8 \%$ of persons migrated from one tract to another in a given year during the 2006-2019 period. As we discuss more in the next section of this paper, these sorts of estimates are sorely needed and extremely valuable for studying regular (e.g., annual or seasonal), local (e.g., tract), and 
very recent (e.g., up to the current year and quarter) migration, particularly in some contexts (e.g., during and after extreme weather events).

In Figure 2, we present estimates of the annual CMP for each of three age groups: young adults, family age adults, and older adults. ${ }^{12}$ These estimates and their associated standard errors are also provided in tabular form in Appendix Table A-3. Estimates from the IRS data are not and cannot be provided because the IRS data are not disaggregated by age. Focusing first on preliminaries, consistent with a long line of research on age patterns of migration (e.g., see Rogers and Castro 1981), the CMPs for young adults are higher than those for family age adults, which, in turn, are higher than those for older adults. These differences are expected because they ultimately reflect different life course stages that include, for example, labor force entry and [peak] working years, as well as retirement and elderly migration (Rogers and Watkins 1987; Wilson 2010). Second, recalling our earlier mention of the slowdown in US internal migration in recent years and decades (Cooke 2013; Frey 2009; Kaplan and SchulhoferWohl 2017; Molloy, Smith, and Wozniak 2011), our results are in line with findings from other studies showing that demographic factors, particularly changing age patterns of migration, may have played a partial role (Cooke 2011).

The results displayed in Figure 2 show that estimates of the CMP for each age group from the CCP are generally within the ballpark of similar estimates from the ACS and CPS. The most noticeable differences are the relatively more pronounced downward and then upward time trends in the CCP estimates before and after 2013 respectively. This decrease and then increase over time is present in all three age groups.

Comparing migration estimates across the different datasets involves, at least in part, some consideration of sample size. The CCP contains information on approximately one million young adults in a given year. The corresponding sample sizes in the ACS and CPS are about 170,000 and 10,000 young adults respectively. One obvious implication of these different sample sizes is that the CCP estimates are more precise. Another implication is that, in the absence of oversampling for migrants in the CCP, ACS, and CPS, simply by virtue of its larger sample size, the CCP captures [more] migrants by default.

\footnotetext{
${ }^{12}$ The proportion of persons in each dataset in each of these three age groups, as well as in the remaining two age groups $(0-24$ and $75+)$, are provided in Appendix Table A-2 to give the reader a portrait of the age distributions and their similarities and differences.
} 
Figure 2: Annual crude migration probability of US internal migration by age group at state, county, and tract levels since 2005 in Consumer Credit Panel, American Community Survey, and Current Population Survey

Panel A. Young adults (age 25-29)

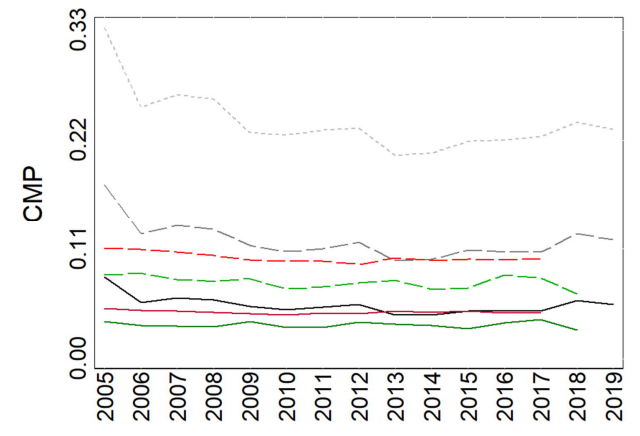

Panel B. Family age adults (age 30-49)

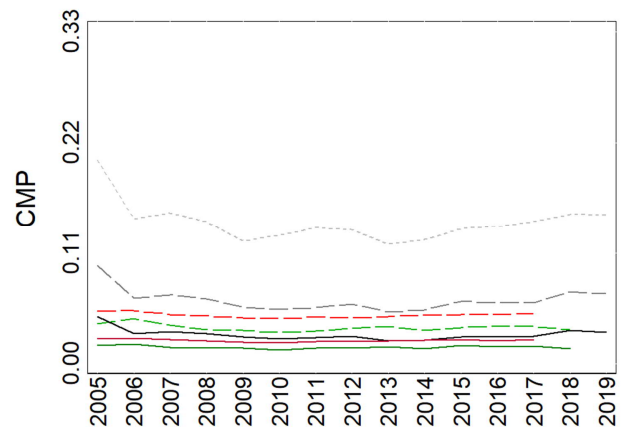


Figure 2: (Continued)

Panel C. Older adults (age 50-74)

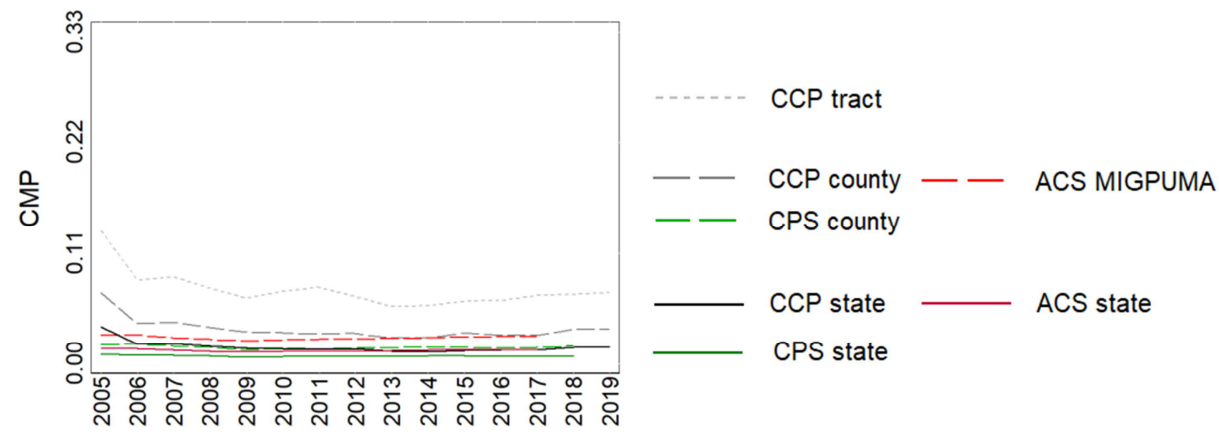

Notes: Selection criteria for analysis provided in Table 1. For ease of display, scales of $y$-axes differ from that in Figure 1. CMP = Crude Migration Probability; CCP = Consumer Credit Panel; ACS = American Community Survey; CPS = Current Population Survey; MIGPUMA = Public Use Microdata Area for Migration. ACS and CPS estimates are weighted.

Another area where the CCP excels relative to the other datasets is with respect to capturing the spatial 'connectivity' of migration (Bell et al. 2002: 452). In Figure 3, we display annual estimates of the $I_{M C}$ at the state, county, and tract levels. Focusing on the state-level estimates in Panel A, the $I_{M C}$ from the CCP and IRS is consistently around 1.0 , meaning that every state is connected to every other state by a migration flow of any size. While this is intuitive, estimates of the $I_{M C}$ from the ACS and CPS fall short on account of their smaller sample sizes. Thus, while the ACS and CPS data are representative of the US population, they are not necessarily representative of all migrations made between US states. As a result, the ACS and CPS data are poorly suited to study the spatial connectivity of migration. 
Figure 3: Annual index of migration connectivity of US internal migration at state, county, and tract levels since 2005 in Consumer Credit Panel, American Community Survey, Current Population Survey, and Internal Revenue Service data

Panel A. State
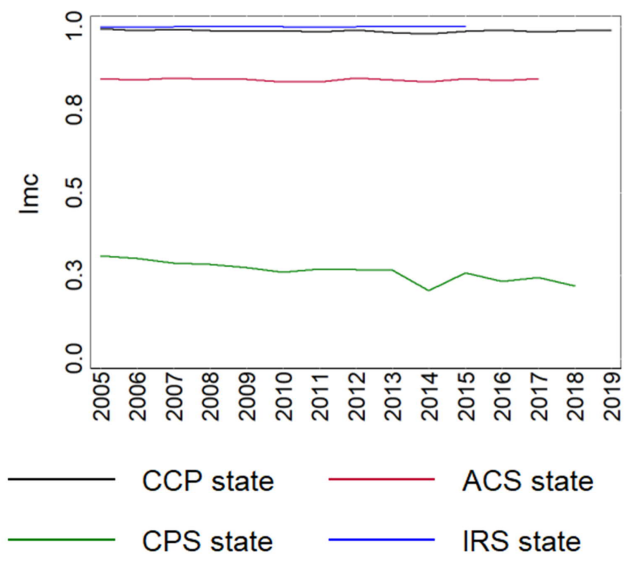

\section{Panel B. County}

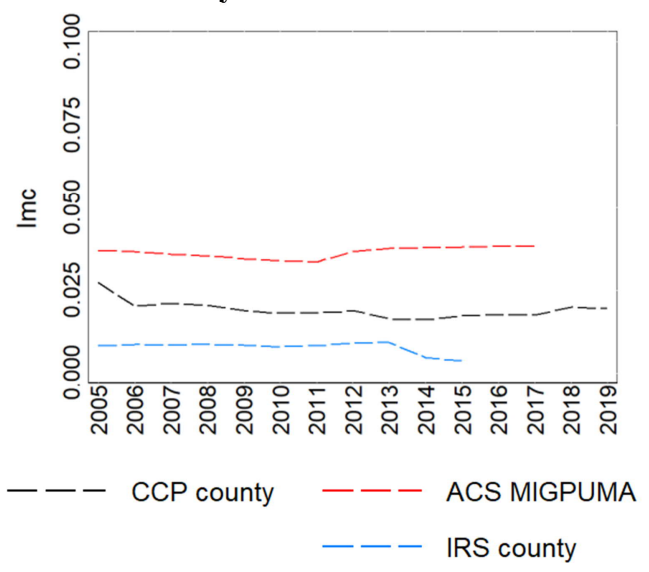




\section{Figure 3: (Continued)}

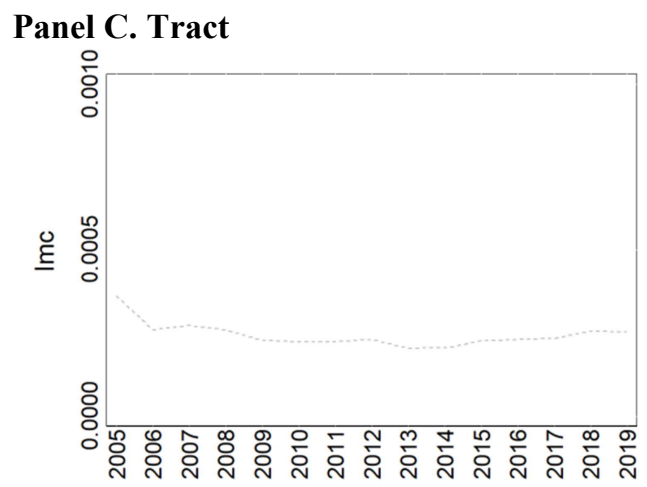

Notes: Selection criteria for analysis provided in Table 1. For ease of display, scales of $y$-axes differ across panels. Imc $=\operatorname{Index}$ of Migration Connectivity; CCP = Consumer Credit Panel; ACS = American Community Survey; CPS = Current Population Survey; IRS = Internal Revenue Service; MIGPUMA = Public Use Microdata Area for Migration. ACS and CPS estimates are weighted.

At the county level, there is considerably less spatial connectivity. As we foreshadowed earlier (see Footnote 11), estimates of the $I_{M C}$ from the ACS are higher than corresponding estimates from the CCP and IRS because MIGPUMAs tend to be larger than counties and are therefore more likely to be connected. The county-level $I_{M C}$ from the CCP has been remarkably stable over time, averaging $1.9 \%$ per year during the 2006-2019 period. The $I_{M C}$ from the IRS has also been stable over time but less so in more recent years, perhaps due in part to the different data processing procedures that were implemented by the IRS in 2011 (Pierce 2015; see also DeWaard et al. 2019). ${ }^{13}$ Finally, considering that there are 73,057 census tracts in the United States, ${ }^{14}$ and $5,337,252,192$ possible migration ties among them, ${ }^{15}$ it is not surprising that the tractlevel $I_{M C}$ from the CCP averaged only $0.02 \%$ during the $2006-2015$ period.

To round out our treatment of the spatial connectivity of migration, in Table 2, we list the CMPS for top five state-to-state migration flows from the CCP in 2015, rankordered the absolute size of flows, and provide corresponding estimates of the $C M P$ from the ACS, CPS, and IRS data. ${ }^{16}$ In Table 3, we do the same but separately for each of the three age groups used earlier: young adults, family age adults, and older adults (Johnson, Winkler, and Rogers 2013). For each state-to-state CMP displayed in these

\footnotetext{
${ }^{13}$ Another potential factor is that county-to-county migration estimates in the IRS are only disclosed for flows comprised of 10 or more households.

${ }^{14}$ See https://www.census.gov/programs-surveys/geography.html.

$155,337,252,192=73,057$ migrant-sending, or origin, tracts $X 73,056$ possible migrant-receiving, or destination, tracts.

${ }^{16}$ We use 2015 since this is the most recent year for which we have data from each these four data sets.
} 
two tables, the estimate from the CCP is roughly comparable to estimates from the other three data sources. As discussed above, the observed differences are ultimately due to differences in the logic, implementation, and shortcomings (e.g., the smaller sample size of the CPS) of these datasets.

Table 2: Top five state-to-state crude migration probabilities of US internal migration in 2015 in Consumer Credit Panel, American Community Survey, Current Population Survey, and Internal Revenue Service data

\begin{tabular}{lcccc}
\hline & CCP & ACS & CPS & IRS \\
\hline 1. New York $\rightarrow$ Florida & 0.00402 & 0.00324 & 0.00302 & 0.00402 \\
2. California $\rightarrow$ Texas & 0.00167 & 0.00165 & 0.00071 & 0.00201 \\
3. New York $\rightarrow$ New Jersey & 0.00264 & 0.00252 & 0.00150 & 0.00357 \\
4. California $\rightarrow$ Nevada & 0.00124 & 0.00157 & 0.00144 & 0.00138 \\
5. Florida $\rightarrow$ Georgia & 0.00211 & 0.00215 & 0.00020 & 0.00262 \\
\hline
\end{tabular}

Notes: Selection criteria for analysis provided in Table 1. CCP = Consumer Credit Panel; ACS = American Community Survey; CPS = Current Population Survey; IRS = Internal Revenue Service. ACS and CPS estimates are weighted.

Table 3: Top five state-to-state crude migration probabilities of US internal migration by age group in 2015 in Consumer Credit Panel, American Community Survey, and Current Population Survey

Panel A. Young adults (age 25-29)

\begin{tabular}{lccc}
\hline & CCP & ACS & CPS \\
\hline 1. California $\rightarrow$ Texas & 0.00360 & 0.00351 & --- \\
2. Texas $\rightarrow$ California & 0.00408 & 0.00383 & --- \\
3. New York $\rightarrow$ Florida & 0.00545 & 0.00462 & 0.01032 \\
4. New York $\rightarrow$ California & 0.00529 & 0.00669 & --- \\
5. New York $\rightarrow$ New Jersey & 0.00522 & 0.00563 & -- \\
\hline
\end{tabular}


Table 3: (Continued)

Panel B. Family age adults (age 30-49)

\begin{tabular}{lccc}
\hline & CCP & ACS & CPS \\
\hline 1. California $\rightarrow$ Texas & 0.00233 & 0.00192 & 0.00111 \\
2. New York $\rightarrow$ New Jersey & 0.00434 & 0.00344 & 0.00318 \\
3. New York $\rightarrow$ Florida & 0.00367 & 0.00259 & 0.00239 \\
4. Florida $\rightarrow$ Georgia & 0.00322 & 0.00225 & -- \\
5. New York $\rightarrow$ California & 0.00309 & 0.00284 & 0.00346 \\
\hline
\end{tabular}

\section{Panel C. Older adults (age 50-74)}

\begin{tabular}{lccc}
\hline & CCP & ACS & CPS \\
\hline 1. New York $\rightarrow$ Florida & 0.00424 & 0.00370 & 0.00173 \\
2. California $\rightarrow$ Nevada & 0.00114 & 0.00130 & 0.00117 \\
3. New York $\rightarrow$ Arizona & 0.00103 & 0.00010 & --- \\
4. California $\rightarrow$ Texas & 0.00100 & 0.00089 & 0.00018 \\
5. Georgia $\rightarrow$ Florida & 0.00343 & 0.00301 & 0.00364
\end{tabular}

Notes: Selection criteria for analysis provided in Table 1. CCP = Consumer Credit Panel; ACS = American Community Survey; CPS = Current Population Survey; IRS = Internal Revenue Service. ACS and CPS estimates are weighted. Due to its small sample size, missing values for some CPS estimates reflect no recorded migration for these state-to-state flows in the age group in question.

Taken together, the results provided and discussed in this section establish the comparative utility and demonstrate some of the unique advantages of the $\mathrm{CCP}$, at least after 2005. In the next section, we turn our attention to a similar set of exercises focusing on longitudinal estimates and comparisons using the CCP and other commonly used data sources.

\subsection{Longitudinal analysis}

\subsubsection{Data}

Excluding the CCP, which we described earlier in Table 1, we describe the other five datasets used in our longitudinal analysis in Table 4. These datasets are similarly characterized by different universes, sample sizes, time spans, and migration information. Unlike in our cross-sectional analyses, it is not possible to develop a single 
set of selection criteria that permit us to simultaneously compare all six datasets to one another. Accordingly, in the final column in Table 4, we provide selection criteria that are specific to each paired comparison between the dataset listed and the CCP (e.g., restricting the age range in the CCP to match the age range in the NLSY79 so that we can compare estimates of migration derived from these two datasets to one another).

Observation windows differ across each paired comparison and, excluding the SIPP04 and SIPP08, cover a roughly ten-year period since 2004 or 2005 . We restrict our focus to within each paired comparison (e.g., we compare migration estimates from the NLSY79 to CCP-equivalent estimates based on implementing the selection criteria in Table 4), and we do not compare across paired comparisons (e.g., we do not compare migration estimates from the NLSY79 and its CCP-equivalent estimates to estimates from the SIPP08 and its CCP-equivalent estimates).

As shown in Table 4, migration measurement intervals differ across the datasets, ranging from monthly in the SIPP04 and SIPP08 to biennially in the NLSY79, NLSY97, and PSID. Datasets with more frequent location measures are likely to capture high frequency moves. For example, an individual who moves between states twice in a two-year period will have both moves captured in the monthly SIPP04, but one or both moves may be missed in the biennial PSID. Accordingly, to compare estimates of migration from each of the datasets listed in Table 4 to its CCP-equivalent estimates, we use the same migration measurement interval in the two datasets (e.g., in comparing migration estimates from the PSID to its CCP-equivalent estimates, we generate the latter estimates using the migration measurement interval in the PSID).

We provide attrition rates and coverage ratios for all six longitudinal datasets in Table 5. The attrition rate measures the fraction of the sample at the beginning of the observation period that does not have complete location histories through the end of the period. This rate is much lower in the CCP than in the other five datasets. One likely reason for this is that borrowers are in legally binding contracts with their creditors. For most individuals, it would be costly and inconvenient to end all credit relationships and thereby exit the set of Equifax credit records from which the CCP is drawn. In contrast, participants can opt out of longitudinal surveys with little or no cost or consequence. The coverage ratio measures the fraction of the sample at the end of the observation period that has complete location histories through the entire period. The coverage ratio of the CCP is lower than that of the NLSY and PSID surveys because first-time borrowers are added to the CCP each year. The CCP is always a combination of complete histories and new entrants. Finally, relative to in the $\mathrm{CCP}$, attrition and coverage are considerably higher and lower, respectively, in the SIPP04 and SIPP08, raising serious concerns about the utility of the SIPP for studying migration (Hernández-Murillo et al. 2011; Zabel 1998). 
Table 4: $\quad$ Descriptions of longitudinal datasets

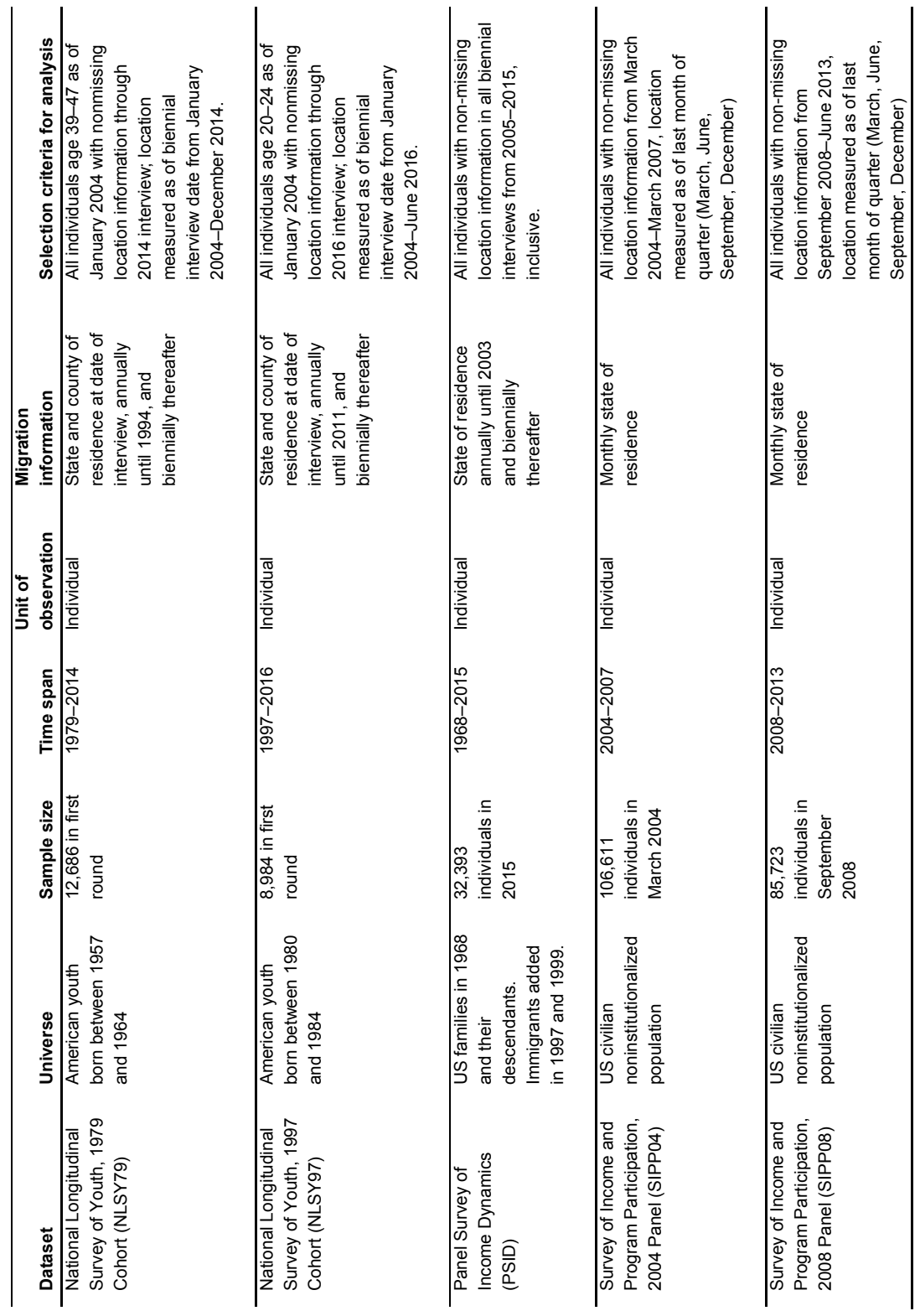


Table 5: Attrition rates and coverage ratios in Consumer Credit Panel, National Longitudinal Survey of Youth (1979 and 1997 cohorts), Panel Study of Income Dynamics, and Survey of Income and Program Participation (2004 and 2008)

\begin{tabular}{lcc}
\hline & Attrition rate & Coverage ratio \\
\hline CCP & 0.090 & 0.793 \\
NLSY79 & 0.220 & 0.920 \\
NLSY97 & 0.265 & 0.862 \\
PSID & 0.319 & 0.900 \\
SIPP04 & 0.742 & 0.665 \\
SIPP08 & 0.783 & 0.585 \\
\hline
\end{tabular}

Notes: CCP = Consumer Credit Panel; NLSY79 = National Longitudinal Survey of Youth, 1979 Cohort; NLSY97 = National Longitudinal Survey of Youth, 1997 Cohort; PSID = Panel Study of Income Dynamics; SIPP04 = Survey of Income and Program Participation 2004; SIPP08 = Survey of Income and Program Participation 2008. Attrition rate is fraction of sample at beginning of observation period with incomplete location histories through end of period. Coverage ratio is fraction of sample at end of observation period with complete histories back to beginning of period. CCP sample contains all individuals with complete panels from Q1 2005 to Q1 2015; locations are derived from current mailing addresses reported by lenders to Equifax. NLSY79 sample contains all individuals age 39-47 as of January 2004 with nonmissing migration information through 2014 interview; location measured as of biennial interview date from January 2004-December 2014. NLSY97 sample contains all individuals age 20-24 as of January 2004 with nonmissing migration information through 2016 interview; location measured as of biennial interview date from January 2004June 2016. PSID observation period spans 2005-2015; location measured biennially. SIPP04 observation period spans March 2004-March 2007; location measured quarterly. SIPP08 observation period spans September 2008-September 2013; location measured quarterly.

\subsubsection{Measures}

Similar to Bell et al. (2002, 2015a, 2015b), Bernard (2017) recently proposed a set of ten longitudinal measures of migration. Among the simplest of these measures, and one that will likely resonate with both migration and fertility scholars, is the Migration Progression Ratio $\left(M P R_{i, i+1}\right)$, which is defined as the proportion a cohort that migrated $i$ times that went on to migration $i+1$ times during the observation window:

$$
M P R_{i, i+1}=\frac{M_{i+1}}{M_{i}} .
$$


Our starting point is to estimate the $M P R_{0,1}$, or the proportion of individuals in each dataset who migrated at least once. We subsequently calculate the $M P R_{0,1}$ for each of the same three age groups in our cross-sectional analysis: young adults between the ages of 25 and 29 at the start of the observation window, family age adults between the ages of 30 and 49, and older adults between the ages of 50 and 74 (Johnson, Winkler, and Rogers 2013). Finally, we estimate the $M P R_{1,2}$ and $M P R_{2,3}$ in order to examine second and third migrations.

Notwithstanding Bernard's (2017) contribution, the set of measures that she proposed is not exhaustive and misses an important and understudied aspect of migration over the life course, which is that, for a variety of reasons, people sometimes return to the places that they had previously migrated from (Eldridge 1965; Johnson and Schulhofer-Wohl 2019). We therefore augment Bernard's (2017) work by incorporating the measure of the Return Migration Ratio $\left(R M R_{j .0, T}\right)$, which we define as the proportion of individuals that resided in place $\mathrm{j}$ at the beginning of the observation window, migrated from $\mathrm{j}$ during the observation window, and returned to $\mathrm{j}$ by the end of the window.

$$
R M R_{j .0, T}=\frac{M_{j, T}}{M_{j}} .
$$

\subsubsection{Results}

Estimates of the $M P R_{0,1}$ at the state, county, and tract levels are displayed in Figure 4. These estimates and their associated standard errors are also provided in tabular form in Appendix Table A-4. Starting with the NLSY79, about $10.9 \%$ and $24.7 \%$ of individuals migrated from one state and one county to another during the observation window respectively. The corresponding CCP-equivalent estimates are $12.7 \%$ and $25.6 \%$, respectively. In the NLSY97, the CCP-equivalent estimates of the $M P R_{0,1}$ are slightly lower than the corresponding estimates in the NLSY97. 
Figure 4: Migration progression ratio of first US internal migration at state, county, and tract levels in Consumer Credit Panel, National Longitudinal Survey of Youth (1979 and 1997 cohorts), Panel Study of Income Dynamics, and Survey of Income and Program Participation (2004 and 2008)

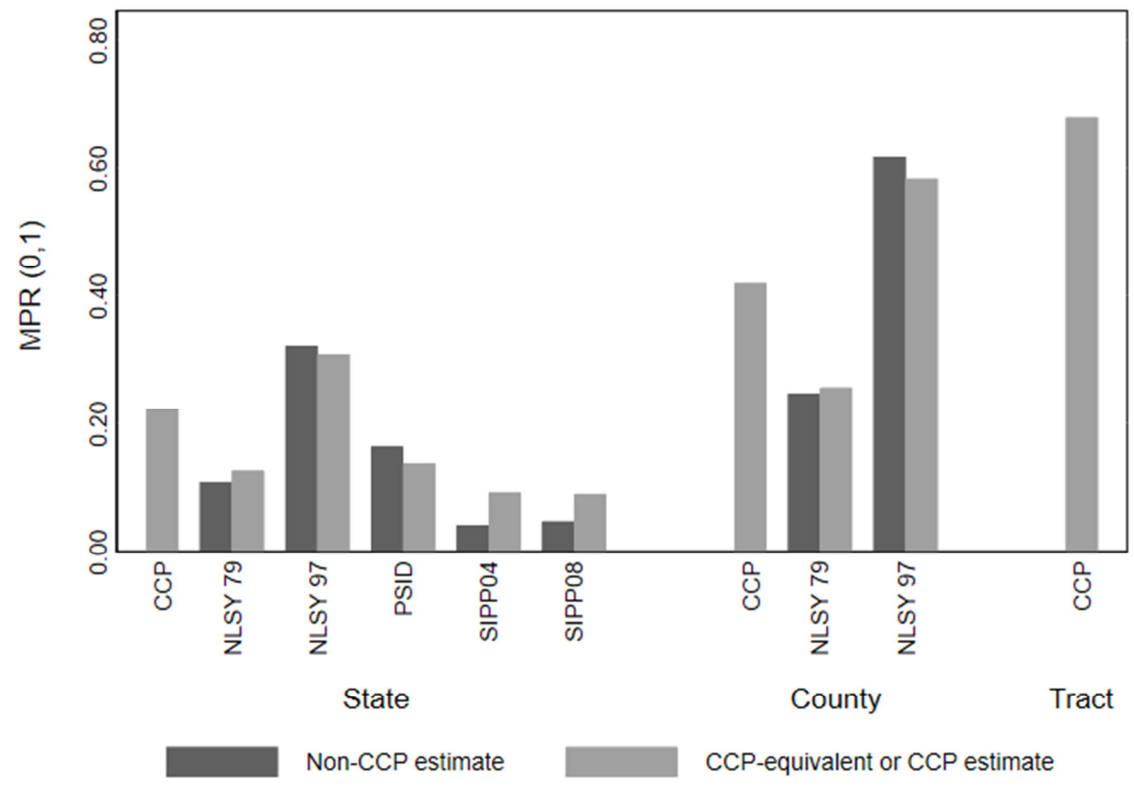

Notes: Selection criteria for analysis provided in Table 4. MPR $(0,1)=$ Migration Progression Ratio of first migration; CCP = Consumer Credit Panel; NLSY79 = National Longitudinal Survey of Youth, 1979 Cohort; NLSY97 = National Longitudinal Survey of Youth, 1997 Cohort; PSID = Panel Study of Income Dynamics; SIPP04 = Survey of Income and Program Participation 2004; SIPP08 = Survey of Income and Program Participation 2008. CCP sample contains all individuals with complete panels from Q1 2005 to Q1 2015; locations are derived from current mailing addresses reported by lenders to Equifax. NLSY79 sample contains all individuals age 39 47 as of January 2004 with nonmissing migration information through 2014 interview; location measured as of biennial interview date from January 2004-December 2014. NLSY97 sample contains all individuals age 20-24 as of January 2004 with nonmissing migration information through 2016 interview; location measured as of biennial interview date from January 2004-June 2016. PSID observation period spans 2005-2015; location measured biennially. SIPP04 observation period spans March 2004-March 2007; location measured quarterly. SIPP08 observation period spans September 2008-September 2013; location measured quarterly.

While estimates of the $M P R_{0,1}$ in the NLSY79 and NLSY97 are similar to their corresponding CCP-equivalent estimates, the observed discrepancies might be due to the fact that the NLSY records location information at the annual interview date, which can occur at any point during the year. In contrast, we used first quarter location information in the CCP. Another explanation for these discrepancies is selection. As we noted earlier, the CCP is a sample of relatively older and more financially established adults. This observation is particularly important for understanding discrepancies 
between estimates of the state and county $M P R_{0,1}$ in the NLSY97 and the corresponding CCP-equivalent estimates. Specifically, individuals in the NLSY97 sample are quite young and were between the ages of 20 and 24 in 2004. Given that the CCP selects older ages by virtue of only including individuals with a credit history (Lee and van der Klaauw 2010; Whitaker 2018), the CCP potentially underestimates migration relative to other datasets and samples composed of younger adults.

Estimates of the state $M P R_{0,1}$ in the PSID and the corresponding CCP-equivalent estimate are also comparable, with reasons for the small observed discrepancy likely similar to those discussed above. Specifically, the PSID records location information at the biennial interview date, which can occur at any time during the year. The PSID is also a representative sample of the entire US resident population, while the CCP only represents adults with a credit score and social security number.

The story is somewhat different for the SIPP04 and SIPP08. Estimates of the state $M P R_{0,1}$ in these datasets are consistently and considerably lower than the corresponding CCP-equivalent estimates. The most likely explanation for these discrepancies is very high attrition in the SIPP (see Table 5). Importantly, in his analysis of attrition in two earlier SIPP panels, the SIPP84 and SIPP90, Zabel (1998) showed that moving between survey waves was strongly positively associated with attrition. Thus, despite the many potential benefits of the SIPP for studying migration described by Hernández-Murillo et al. (2011), the SIPP04 and SIPP08 probably substantially underestimate migration.

Focusing on the $M P R_{0,1}$ at the tract level in the CCP, more than two-thirds $(68.1 \%)$ of the sample migrated from one tract to another during the observation window. Given that we cannot corroborate this estimate against similar estimates from the NLSY79, NLSY97, PSID, SIPP04, and SIPP08, we took the selection criteria used to calculate the $M P R_{0,1}$ at the tract level in the CCP and used these to estimate the corresponding state and county $M P R_{0,1}$ in the CCP to ensure that the latter two estimates were lower than the former. As is evident in Figure 4, the state $M P R_{0,1}$ is lower than the county $M P R_{0,1}$, which, in turn, is lower than the tract $M P R_{0,1}$.

In Figure 5, we present estimates of the $M P R_{0,1}$ for each of three age groups: young adults, family age adults, and older adults. ${ }^{17}$ These estimates and their associated standard errors are also provided in tabular form in Appendix Table A-5. Recalling our earlier discussion of age patterns of migration as a reflection of the life course (Rogers and Castro 1981), younger adults are more mobile than family age adults, who, in turn, are more mobile than older adults at all geographic levels. For each age group, the

\footnotetext{
${ }^{17}$ We do not include estimates from the NLSY79 and NLSY97 in Figure 5 because the NLSY is age limited by design. Those in the NLSY79 were between the ages of 39 and 47 in 2004 and thus a subset of the "family age adults' category. Those in the NLSY97 were between the ages of 20 and 24 in 2004 and thus younger than those in the 'young adults' age category.
} 
estimate of the state $M P R_{0,1}$ in the PSID is highly similar to the corresponding CCPequivalent estimate. In contrast, age-specific estimates of the state $M P R_{0,1}$ in the SIPP04 and SIPP08 are less comparable to their corresponding CCP-equivalent estimates, especially among the most mobile young adults.

Figure 5: Migration progression ratio of first US internal migration by age group at state, county, and tract levels in the Consumer Credit Panel and the Panel Study of Income Dynamics

Panel A. Young adults (age 25-29)

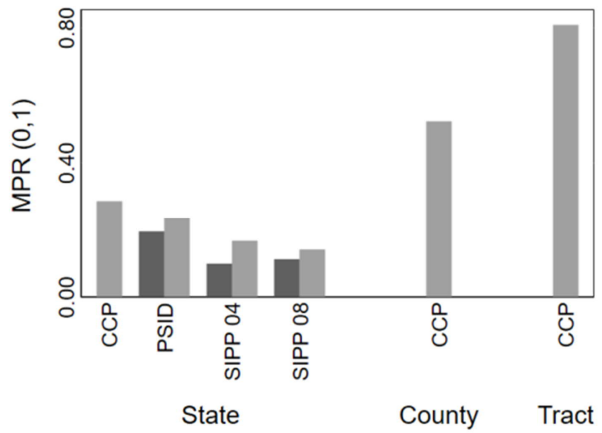

Panel B. Family age adults (age $30-49$ )

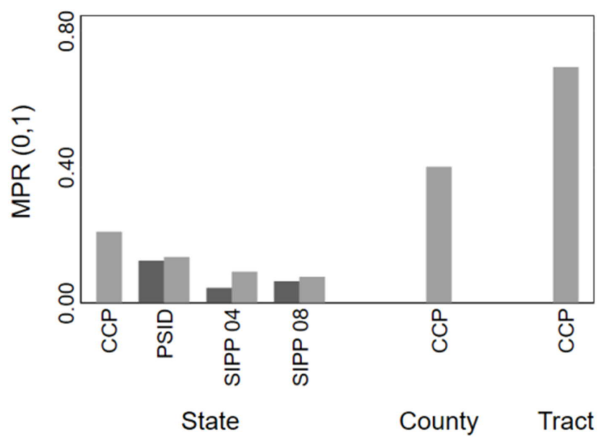

Panel C. Older adults (age 50-74)

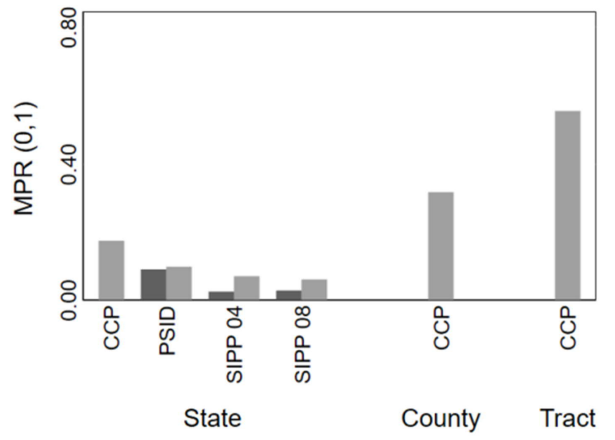

Non-CCP estimate

CCP-equivalent or CCP estimate

Notes: Selection criteria for analysis provided in Table 4. MPR $(0,1)=$ Migration Progression Ratio of first migration; CCP = Consumer Credit Panel; NLSY79 = National Longitudinal Survey of Youth, 1979 Cohort; NLSY97 = National Longitudinal Survey of Youth, 1997 Cohort; PSID = Panel Study of Income Dynamics; SIPP04 = Survey of Income and Program Participation 2004 ; SIPP08 = Survey of Income and Program Participation 2008. CCP sample contains all individuals with complete panels from Q1 2005 to Q1 2015; locations are derived from current mailing addresses reported by lenders to Equifax. PSID observation period spans 2005-2015; location measured biennially. 
Estimates of the $M P R_{1,2}$ and $M P R_{2,3}$ at the state, county, and tract levels are displayed in Figure 6. These estimates and their associated standard errors also provided in Appendix Table A-6. Similar to our discussion of Figures 4 and 5, there are two main take-away messages from the estimates displayed in Figure 6. First, the CCPequivalent estimates are roughly in line with corresponding estimates from the NLSY79, NLSY97, PSID, SIPP04, and SIPP08. Second, any observed discrepancies are due to differences in the implementation of these surveys with respect to such features as recording location information, selection, attrition, and more.

\section{Figure 6: Migration progression ratios of second and third US internal} migration at state, county, and tract levels in Consumer Credit Panel, National Longitudinal Survey of Youth (1979 and 1997 cohorts), Panel Study of Income Dynamics, and Survey of Income and Program Participation (2004 and 2008)

Panel A. Second migration

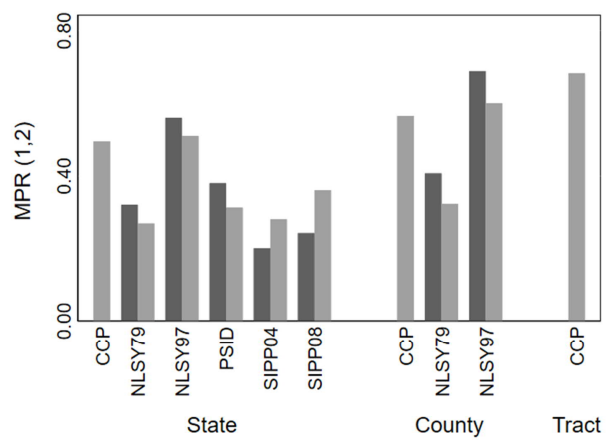

Non-CCP estimate
Panel B. Third migration

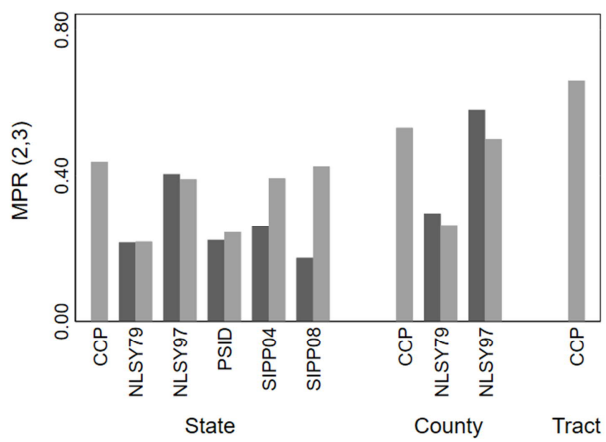

CCP-equivalent or CCP estimate

Notes: Selection criteria for analysis provided in Table 4. MPR $(1,2)=$ Migration Progression Ratio of second migration; MPR $(2,3)=$ Migration Progression Ratio of third migration; CCP = Consumer Credit Panel; NLSY79 = National Longitudinal Survey of Youth, 1979 Cohort; NLSY97 = National Longitudinal Survey of Youth, 1997 Cohort; PSID = Panel Study of Income Dynamics; SIPP04 = Survey of Income and Program Participation 2004; SIPP08 = Survey of Income and Program Participation 2008. CCP sample contains all individuals with complete panels from Q1 2005 to Q1 2015; locations are derived from current mailing addresses reported by lenders to Equifax. NLSY79 sample contains all individuals age 39-47 as of January 2004 with nonmissing migration information through 2014 interview; location measured as of biennial interview date from January 2004-December 2014. NLSY97 sample contains all individuals age 20-24 as of January 2004 with nonmissing migration information through 2016 interview; location measured as of biennial interview date from January 2004-June 2016. PSID observation period spans 2005-2015; location measured biennially. SIPP04 observation period spans March 2004-March 2007; location measured quarterly. SIPP08 observation period spans September 2008-September 2013; location measured quarterly. 
At the tract level, $68.4 \%$ of individuals in the $\mathrm{CCP}$ who had migrated once went on to migrate a second time. Of these, $66.3 \%$ went on to migrate a third time. Again, because we cannot corroborate these estimates against similar estimates from the NLSY79, NLSY97, PSID, SIPP04, and SIPP08, we took the selection criteria used to calculate the $M P R_{1,2}$ and $M P R_{2,3}$ at the tract level in the CCP and used these to estimate the corresponding state and county $M P R_{1,2}$ and $M P R_{2,3}$ in the CCP to ensure that the state estimates were lower than the corresponding county estimates and that the county estimates were lower than the corresponding tract estimates.

Going beyond the set of longitudinal measures of migration proposed by Bernard (2017), we present estimates of the $R M R_{j .0, T}$ in Figure 7, with corresponding estimates and standard errors provided in tabular form in Appendix Table A-7. For each paired comparison, the $R M R_{j .0, T}$ in the NLSY79, NLSY97, and PSID is higher than the corresponding CCP-equivalent estimate. Having already discussed several potential candidate explanations for these discrepancies, the final step in our analysis is to verify that, in the CCP, the tract $R M R_{j .0, T}$ is lower than the county $R M R_{j .0, T}$, which, in turn, is lower than the state $R M R_{j .0, T}$. In substantive terms, this means that individuals are much more likely to return to their state and county and not necessarily their census tract (crudely, their neighborhood), of origin.

As we noted earlier in Section 3, unlike in other datasets, there is less of a tradeoff between geographic and temporal specificity in the CCP. To see this more clearly, following a growing body of research on migration from and to affected areas after extreme weather disasters in the United States (Fussell, Curtis, and DeWaard 2014; Groen and Polivka 2010; Myers, Slack, and Singelmann 2008), we estimate the $R M R_{j .0, T}$ in the year after the three costliest hurricanes in US history - in order, these include Hurricanes Katrina, Harvey, and Maria - two of which occurred fairly recently in 2017 (NOAA 2019). For Hurricanes Katrina and Harvey, we consulted the Spatial Hazards Events and Losses Database for the United States (SHELDUS) to select the county that incurred the greatest economic losses from property damage. These counties include Orleans Parish, LA, and Harris County, TX, respectively. For Hurricane Maria, we focus on Puerto Rico as a whole. 
Figure 7: Return migration ratio of US internal migration at state, county, and tract levels in Consumer Credit Panel, National Longitudinal Survey of Youth (1979 and 1997 cohorts), and Panel Study of Income Dynamics

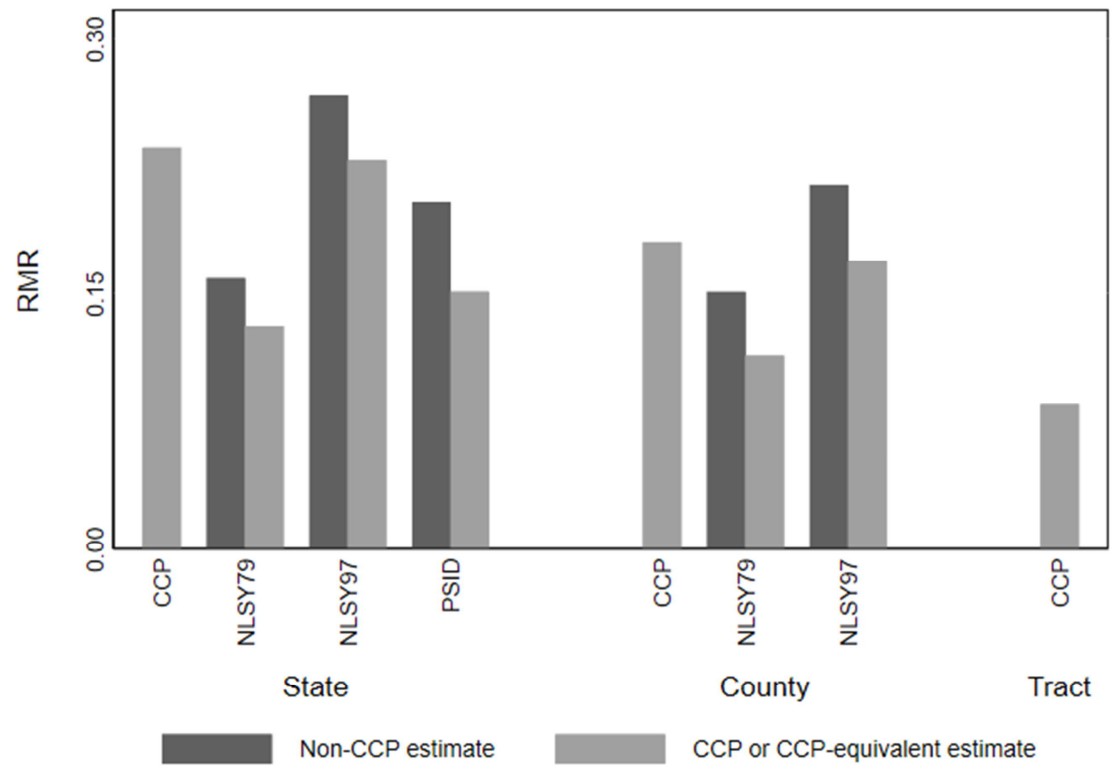

Notes: Selection criteria for analysis provided in Table 4. RMR $=$ Return Migration Ratio; $\mathrm{CCP}=$ Consumer Credit Panel; NLSY79 = National Longitudinal Survey of Youth, 1979 Cohort; NLSY97 = National Longitudinal Survey of Youth, 1997 Cohort; PSID = Panel Study of Income Dynamics. CCP sample contains all individuals with complete panels from Q1 2005 to Q1 2015; locations are derived from current mailing addresses reported by lenders to Equifax. NLSY79 sample contains all individuals age 39-47 as of January 2004 with nonmissing migration information through 2014 interview; location measured as of biennial interview date from January 2004-December 2014. NLSY97 sample contains all individuals age 20-24 as of January 2004 with nonmissing migration information through 2016 interview; location measured as of biennial interview date from January 2004-June 2016. PSID observation period spans 2005-2015; location measured biennially.

In Figure 8, we display the $R M R_{j .0, T}$ for each county and Puerto Rico one, two, three, and four quarters after Hurricanes Katrina, Harvey, and Maria made landfall in August 2005, August 2017, and September 2017 respectively. In each case, the $R M R_{j .0, T}$ increased over successive quarters, a finding that is consistent with the three characteristic phases of post-disaster recovery-emergency, restoration, and reconstruction - described by Kates et al. (2006). However, with respect to levels of the $R M R_{j .0, T}$, the situation in Puerto Rico clearly differs from the other two cases. This is likely due to the relatively higher cost of migrating from and to Puerto Rico, as well as the lingering effects of Puerto Rico's economic crisis that began in 2006 and the poorly 
managed disaster response to Hurricane Maria (Meléndez and Hinojosa 2017; Rodríguez-Díaz 2018; Zorrilla 2017).

Figure 8: Return migration ratio by quarter in Consumer Credit Panel for selected disaster-affected areas after the three costliest hurricanes in US history

Panel A. Orleans Parish, LA, after Hurricane Katrina

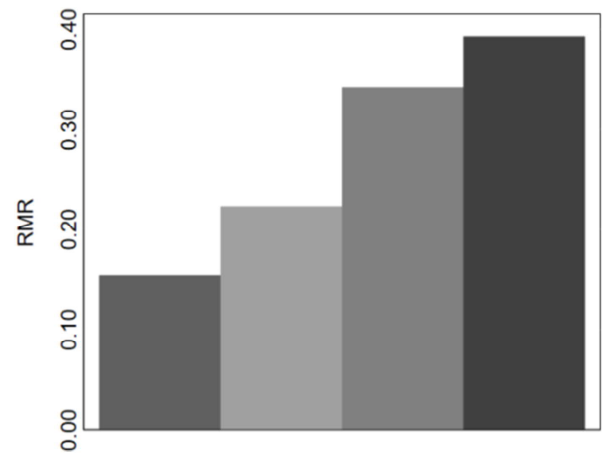

Panel B. Harris County, TX, after Hurricane Harvey

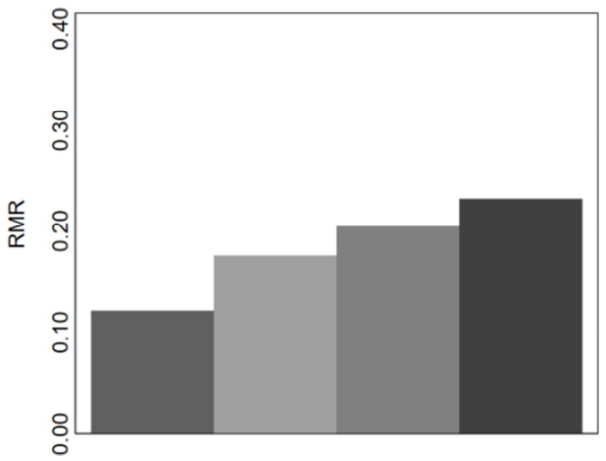

\section{Panel C. Puerto Rico after Hurricane Maria}

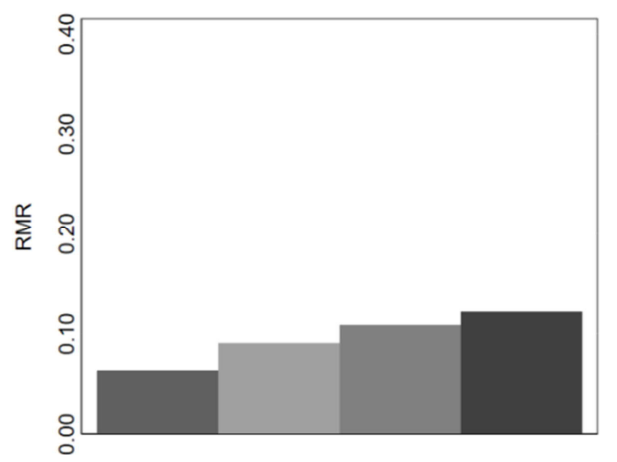

Notes: The return migration ratio is the fraction of those who resided in the disaster-affected area in the quarter prior to the hurricane and migrated from the area in the quarter when the hurricane made landfall (2005-Q3 for Hurricane Katrina and 2017-Q3 for Hurricanes Harvey and Maria) who migrated to the area in the quarter shown in each of the panels. 
In Figure 9, we go one step further. For each case, we display the $R M R_{j .0, T}$ for two groups of census tracts in the year after each hurricane. Given the importance of storm surge and flooding during and after hurricanes, we define 'water tracts' as those with more than $1 \%$ water area and distinguish these from 'non-water tracts. ${ }^{18}$ In the year after Hurricane Katrina, $40.2 \%$ of those who initially resided in a non-water tract and migrated from Orleans Parish returned to Orleans Parish; however, only 31.4\% returned to the same tract. Far fewer returned to Orleans Parish and to a different tract, with most returning to non-water tracts. A similar pattern holds for those who initially resided in a water tract and migrated from and then to Orleans Parish after Hurricane Katrina, as well as for return migration to Harris County after Hurricane Harvey. In contrast, nearly all return migrants to Puerto Rico in the year following Hurricane Maria returned to the same tract: $11.5 \%$ and $13.5 \%$ who initially resided in non-water and water tracts return to Puerto Rico, respectively, with $10.6 \%$ and $11.4 \%$ returning to the same tract.

\section{Figure 9: One-year return migration ratio in Consumer Credit Panel for non- water and water tracts in selected disaster-affected areas and after the three costliest hurricanes in US history}

\section{Panel A. Orleans Parish, LA, after Hurricane Katrina}

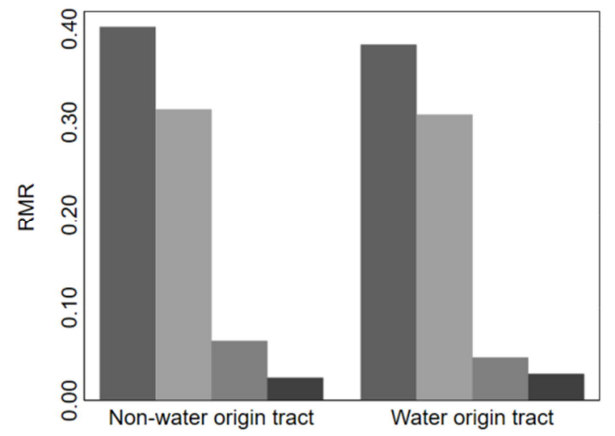

Panel B. Harris County, TX, after Hurricane Harvey

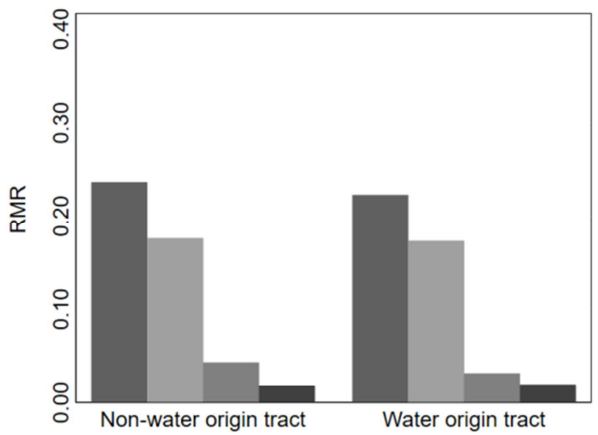

${ }^{18}$ Under this definition and using 2000 census tracts, we classified $56(31 \%)$ of the 181 tracts in Orleans Parish, 165 (25\%) of the 649 tracts in Harris County, and 288 (34\%) of the 861 tracts in Puerto Rico as water tracts. 
Figure 9: (Continued)

\section{Panel C. Puerto Rico after Hurricane Maria}
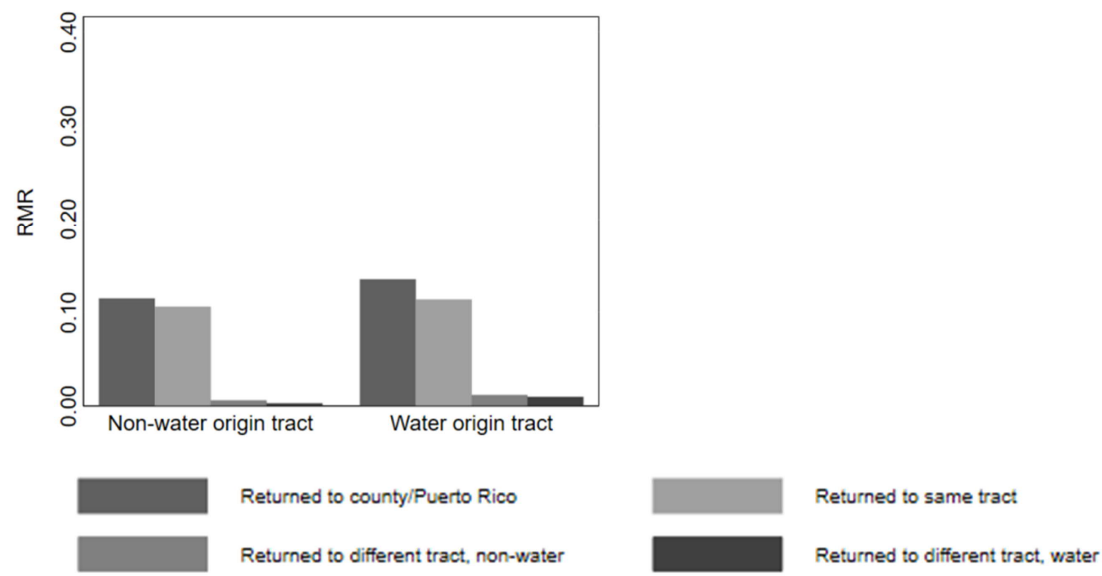

Notes: The return migration ratio is the fraction of those who resided in the disaster-affected area in the quarter prior to the hurricane and migrated from the area in the quarter when the hurricane made landfall (2005-Q3 for Hurricane Katrina and 2017-Q3 for Hurricanes Harvey and Maria) who migrated to the area in the year after the hurricane. Water tracts are defined as those with more than $1 \%$ water area within their boundaries. All other tracts are defined as non-water tracts.

Taken together, the results provided and discussed in this section further establish the comparative utility of the CCP. They also illustrate some of the unique advantages of the CCP with respect to both geographic and temporal specificity.

\section{Discussion}

In this paper, we provided the first comprehensive comparative assessment of the CCP to demonstrate the utility and unique advantages of these data for research on internal migration in the United States (Lee and van der Klaauw 2010; Whitaker 2018). We did so because the CCP better resolves two persistent problems that plague other crosssectional and longitudinal datasets. First, due to its very large sample size of about 10 million borrowers per year, the CCP requires less of a tradeoff between temporal and geographic specificity, which, in turn, permits portraits of simultaneously regular (down to the quarter) and local (down to the census block of borrowers) migration. Second, the construction of the CCP is such that problems of follow-up and attrition are considerably less severe.

The comparative utility and unique advantages of the CCP warrant greater use of these data in future research on US internal migration. As we briefly showed at the end 
of the previous section, one area that would particularly benefit from these data is research on migration and population displacement in response to climate and environmental shocks and corresponding economic effects (Boustan et al. 2017; Fussell, Curtis, and DeWaard 2014; Gallagher and Hartley 2017; Groen and Polivka 2010; Hunter, Luna, and Norton 2015; Myers, Slack, and Singelmann 2008; Tran and Sheldon 2018). Specifically, the CCP affords the opportunity to study the demographic and economic implications of both rapid and slow-onset shocks at different time intervals and spatial scales. The CCP data are also available up to the most recent quarter, which makes them particularly well-suited for studying very recent shocks like Hurricanes Florence and Michael in the fall of 2018, as well as other types of shocks like the Mendocino Complex Wildfire in California earlier that summer. Future work could also use the CCP to examine differences in migration and return migration patterns by age, as well as other characteristics provided in the CCP data or merged from other datasets.

In pursuing this and other research, it is important to also keep in mind the many weaknesses of the CCP. Bracketing the issue of accessibility given the proprietary nature of these data, perhaps the greatest weaknesses of the CCP, especially in the context of studying climate and environmental shocks, is that CCP is a sample of relatively older and more financially established adults. Relative to younger and less financially established adults, those in the CCP not only have more resources at their disposal to adapt to climate and environmental shocks in-situ, they can also use these resources to overcome the sometimes prohibitive costs of migration that might trap others in place (Black et al. 2011; Bodvarsson and Van den Berg 2013; Nawrotzki and DeWaard 2018).

The above limitations notwithstanding, the central contribution of this paper is to provide a much needed introduction to the $\mathrm{CCP}$ and a comprehensive comparative point of reference. The CCP data are a valuable and underutilized resource for studying US internal migration. While descriptive, we hope that our work in this paper will help to stimulate future efforts to use these and other nontraditional sources of data, such as social media data (Cesare et al. 2018), to study migration. In the process, we hope that the use of the CCP and other nontraditional sources of migration data will contribute to important conversations about [improving] the availability, quality, and comparability of migration data more generally. The $\mathrm{CCP}$ and other nontraditional sources of migration data might be used to evaluate the quality, such as coverage and content (see Preston, Heuveline, and Guillot 2001), of migration information contained in traditional censuses and surveys, as well as to develop harmonized data on and estimates of migration (Raymer et al. 2013). As several recently published high-level papers and books on the state of migration research have argued (Raymer, Willekens, and Rogers 2018; White 2016; Willekens et al. 2016), the future of migration research and its 
intersections with the work of policymakers and practitioners is very much bound up with the availability, quality, and comparability of migration data. Data on internal migration in the United States are no exception.

\section{Acknowledgements}

DeWaard and Johnson acknowledge support from center grant \#P2C HD041023 awarded to the Minnesota Population Center at the University of Minnesota by the Eunice Kennedy Shriver National Institute of Child Health and Human Development. DeWaard and Johnson also acknowledge research assistance provided by Morrison (Luke) Smith with financial support from the Minnesota Population Center and by David Van Riper. Earlier versions of this paper were presented at the annual meeting of the Population Association of America on April 12, 2019, the Center for Economic Research and Graduate Education - Economics Institute on November 29, 2018, the Max Planck Institute for Demographic Research on November 27, 2018, the University of Groningen on November 22, 2018, the Urban Institute on November 6, 2018, and the Federal Reserve Bank of Atlanta on August 21, 2018. The authors wish to thank members of these audiences for their helpful comments and are particularly grateful for feedback provided by Rebbeca Tesfai, Sam Schulhofer-Wohl, and Emilio Zagheni. 


\section{References}

Abel, G.J. (2018). Estimates of global bilateral migration flows by gender between 1960 and 2015. International Migration Review 52(3): 809-852. doi:10.1177/ 0197918318781842.

Abel, G.J. and Sander, N. (2014). Quantifying global international migration flows. Science 343(6178): 1520-1522. doi:10.1126/science.1248676.

Abowd, J.M. (2018). The US Census Bureau adopts differential privacy. Paper presented at $24^{\text {th }}$ ACM SIGKDD International Conference on Knowledge Discovery and Data Mining, London, UK, August 19-23, 2018. doi:10.1145/ 3219819.3226070 .

Ali, S. and Hartmann, D. (2015). Migration, incorporation, and change in an interconnected world. New York: Routledge. doi:10.4324/9781315733036.

Bell, M., Blake, M., Boyle, P., Duke-Williams, O., Rees, P., Stillwell, J., and Hugo, G. (2002). Cross-national comparison of internal migration: Issues and measures. Journal of the Royal Statistical Society: Series A (Statistics in Society) 165(3): 435-464. doi:10.1111/1467-985X.t01-1-00247.

Bell, M., Charles-Edwards, E., Kupiszewska, D., Kupiszewski, M., Stillwell, J., and Zhu, Y. (2015a). Internal migration data around the world: Assessing contemporary practice. Population, Space, and Place 21(1): 1-17. doi:10.1002/ psp.1848.

Bell, M., Charles-Edwards, E., Ueffing, P., Stillwell, J., Kupiszewski, M., and Kupiszewska, D. (2015b). Internal migration and development: Comparing migration intensities around the world. Population and Development Review 41(1): 33-58. doi:10.1111/j.1728-4457.2015.00025.x.

Bernard, A. (2017). Cohort measures of internal migration: Understanding long-term trends. Demography 54(6): 2201-2221. doi:10.1007/s13524-017-0626-7.

Black, R., Bennett, S.R.G., Thomas, S.M, and Beddington, J. (2011). Migration as adaptation. Nature 478: 447-449. doi:10.1038/478477a.

Bodvarsson, Ö.B. and Van den Berg, H. (2013). The economics of immigration: Theory and policy ( $2^{\text {nd }}$ ed.). New York: Springer. doi:10.1007/978-1-4614-2116-0. 
Boustan, L.P., Kahn, M.E., Rhode, P.W., and Yanguas, M.L. (2017). The effect of natural disasters on economic activity in US counties: A century of data. Cambridge, MA: National Bureau of Economic Research (NBER Working Paper 23410). doi:10.3386/w23410.

Brettell, C. and Hollifield J.F. (2015). Migration theory: Talking across disciplines $\left(3^{\text {rd }}\right.$ ed.). New York: Routledge. doi:10.4324/9781315814933.

Brevoort, K.P., Grimm, P., and Kambara, M. (2016). Credit invisibles and the unscored. Cityscape 18: 9-33. doi:10.2139/ssrn.2743007.

Castles, S., de Haas, H., and Miller, M.J. (2014). The age of migration: International population movements in the modern world ( $5^{\text {th }}$ ed.). New York: Palgrave Macmillan. doi:10.1007/978-0-230-36639-8.

Cesare, N., Lee, H., McCormick, T., Spiro, E., and Zagheni, E. (2018). Promises and pitfalls of using digital traces for demographic research. Demography 55(5): 1979-1999. doi:10.1007/s13524-018-0715-2.

Cooke, T.J. (2011). It is not just the economy: Declining migration and the rise of secular rootedness. Population, Space and Place 17(3): 193-203. doi:10.1002/ psp.670.

Cooke, T.J. (2013). Internal migration decline. The Professional Geographer 65(4): 664-675. doi:10.1080/00330124.2012.724343.

DeWaard, J., Fussell, E., Curtis, K.J., and Ha, J.T. (2017). Changing spatial interconnectivity during the 'Great American Migration Slowdown': A decomposition of inter-county migration rates, 1990-2010. Population, Space and Place.

DeWaard, J., Ha, J.T., Raymer, J., and Wiśniowski, A. (2017). Migration from newaccession countries and duration expectancy in the EU-15: 2002-2008. European Journal of Population 33(1): 33-53. doi:10.1007/s10680-016-9383-3.

Ding, L., Hwang, J., and Divringi, E. (2016). Gentrification and residential mobility in Philadelphia. Regional Science and Urban Economics 61: 38-51. doi:10.1016/ j.regsciurbeco.2016.09.004.

Eldridge, H.T. (1965). Primary, secondary, and return migration in the United States, 1955-60. Demography 2(1): 444-455. doi:10.2307/2060130.

Fitzgerald, J.M. (2011). Attrition in models of intergenerational links using the PSID with extensions to health and sibling models. The B.E. Journal of Economic Analysis and Policy 11(3): 1-61. doi:10.2202/1935-1682.2868. 
Fitzgerald, J.M., Gottschalk, P., and Moffitt, R. (1998). An analysis of the impact of sample attrition on the second generation of respondents in the Michigan Panel Study of Income Dynamics. The Journal of Human Resources 33(2): 300-344. doi:10.2307/146434.

Frey, W.H. (2009). The great American migration slowdown: Regional and metropolitan dimensions. Metropolitan Policy Program. Washington, D.C.: The Brookings Institution.

Frey, W.H. (2017). Census shows a revival of pre-recession migration flows. Metropolitan Policy Program. Washington, D.C.: The Brookings Institution.

Fussell, E., Curtis, K.J., and DeWaard, J. (2014). Recovery migration to the City of New Orleans after Hurricane Katrina: A migration systems approach. Population and Environment 35(3): 305-322. doi:10.1007/s11111-014-0204-5.

Gallagher, J. and Hartley, D. (2017). Household finance after a natural disaster: The case of Hurricane Katrina. American Economic Journal: Economic Policy 9(3): 199-228. doi:10.1257/pol.20140273.

Grecequet, M., DeWaard, J., Hellmann, J.J., and Abel, G.J. (2017). Climate vulnerability and human migration in global perspective. Sustainability 9(5): 720. doi:10.3390/su9050720.

Groen, J.A. and Polivka, A.E. (2010). Going home after Hurricane Katrina: Determinants of return migration and changes in affected areas. Demography 47(4): 821-844. doi:10.1007/BF03214587.

Gross, E. (2005). Internal Revenue Service area-to-area migration data: Strengths, limitations, and current trends. Statistics of Income Division. Washington, D.C.: Internal Revenue Service.

Hernández-Murillo, R., Ott, L.S., Owyang, M.T., and Whalen, D. (2011). Patterns of interstate migration in the United States from the Survey of Income and Program Participation. Federal Reserve Bank of St. Louis Review 93(3): 169-185. doi:10.20955/r.93.169-186.

Hill, M.S. (1992). The Panel Study of Income Dynamics: A user's guide. Beverley Hill: Sage.

Hunter, L.M., Luna, J.K., and Norton, R.M. (2015). Environmental dimensions of migration. Annual Review of Sociology 41: 377-397. doi:10.1146/annurev-soc073014-112223. 
Hwang, J. (2018). The new housing crisis: Gentrification and residential instability in the Bay Area, 2009-2017. Paper presented at annual meeting of the Association for Public Policy Analysis and Management, Washington D.C., November 8, 2018.

IOM (2018). World migration report 2018. Geneva: International Organization for Migration.

Isserman, A.M., Plane, D.A., and McMillen, D.B. (1982). Internal migration in the United States: An Evaluation of Federal Data. Review of Public Data Use 10: $285-311$.

Johnson, J.E. and Schulhofer-Wohl, S. (2019). Changing patterns of geographic mobility and the labor market for young adults. Journal of Labor Economics 37(S1): S199-S241. doi:10.1086/700887.

Johnson, K.M., Winkler, R., and Rogers, L.T. (2013). Age and lifecycle patterns driving US migration shifts. Durham, NH: Carsey Institute, University of New Hampshire (Issue Brief 62).

Johnson, R.V., Bland, J.M., and Coleman, C.D. (2008). Impacts of the 2005 Gulf coast hurricanes on domestic migration: The US Census Bureau's response. Paper presented at the annual meeting of the Population Association of America, New Orleans, LA, April 17-19.

Kaplan, G. and Schulhofer-Wohl, S. (2012). Interstate migration as fallen less than you think: Consequences of hot deck imputation in the Current Population Survey. Demography 49(3): 1061-1074. doi:10.1007/s13524-012-0110-3.

Kaplan, G. and Schulhofer-Wohl, S. (2017). Understanding the long-run decline in interstate migration. International Economic Review 58(1): 57-94. doi:10.1111/ iere. 12209 .

Kates, R.W., Colten, C.E., Laska, S., and Leatherman, S.P. (2006). Reconstruction of New Orleans after Hurricane Katrina: A research perspective. Proceedings of the National Academy of Sciences of the United States of America 103(40): 1465314660. doi:10.1073/pnas.0605726103.

Koerber, K. (2007). Comparison of ACS and ASEC data on geographic mobility: 2004. Washington, D.C.: US Census Bureau (Census Working Papers). https://www.census.gov/content/dam/Census/library/working-papers/2007/acs/ 2007_Koerber_01.pdf. 
Lee, D. and van der Klaauw, W. (2010). An introduction to the FRBNY Consumer Credit Panel. New York, NY : Federal Reserve Bank of New York (Federal Reserve Bank of New York Staff Reports 479.) doi:10.2139/ssrn.1719116.

Levine, D.B., Hill, K., and Warren, R. (1985). Immigration statistics: A story of neglect. Washington D.C.: National Academy Press.

Lilliard, L.A. and Panis, C.W. (1994). Panel attrition from the PSID: Household income, marital status, and mortality. Santa Monica, CA: RAND Corporation (Labor and Population Program Working Paper Series 94-16).

Long, K. (2015). From refugee to migrant? Labor mobility's protection potential. Washington D.C.: Migration Policy Institute (MPI Reports).

Long, L. (1988). Migration and residential mobility in the United States. New York: Russell Sage Foundation.

Massey, D.S., Arango, J., Hugo, G., Kouaouci, A., Pellegrino, A., and Taylor, J.E. (1998). Worlds in motion: Understanding international migration at the end of the Millennium. Oxford: Oxford University Press.

Massey, D.S. and España, F.G. (1987). The social process of international migration. Science 237(4816): 733-738. doi:10.1126/science.237.4816.733.

Massey, D.S., Pren, K.A., and Durand, J. (2016). Why border enforcement backfired. American Journal of Sociology 121(5): 1557-1600. doi:10.1086/684200.

Meléndez, E. and Hinojosa, J. (2017). Estimates of post-Hurricane Maria Exodus from Puerto Rico. New York: Center for Puerto Rican Studies, The City University of New York (Research Brief RB2017-01).

Merli, M.G., DeWaard, J., Tian, F., and Hertog, S. (2009). Migration and gender in China's HIV/AIDS epidemic. In: Tucker, J. and Poston, D.L. (eds.). Gender policy and HIV in China: Catalyzing policy change. New York: Springer: 2753. doi:10.1007/978-1-4020-9900-7_3.

Molloy, R. and Shan, H. (2013). The postforeclosure experience of US households. Real Estate Economics 41(2): 225-254. doi:10.1111/j.1540-6229.2012.00344.x.

Molloy, R., Smith, C.L., and Wozniak, A. (2011). Internal migration in the United States. Journal of Economic Perspectives 25(3): 173-196. doi:10.1257/jep.25. 3.173 . 
Morgan, J.N. (1979). Memo on the representativeness of the Panel Study of Income Dynamics. Ann Arbor, MI: Survey Research Center, Institute for Social Research, University of Michigan (Technical Paper Series 79-01).

Myers, C. A., Slack, T., and Singelmann, J. (2008). Social vulnerability and migration in the wake of disaster: The case of Hurricanes Katrina and Rita. Population and Environment 29(6): 271-291. doi:10.1007/s11111-008-0072-y.

National Academies of Sciences, Engineering, and Medicine (2017). The economic and fiscal consequences of immigration. Washington D.C.: The National Academies Press.

Nawrotzki, R.J. and DeWaard, J. (2018). Putting trapped populations into place: Climate change and inter-district migration flows in Zambia. Regional Environmental Change 18(2): 533-546. doi:10.1007/s10113-017-1224-3.

NOAA (2019). US billion-dollar weather and climate disasters. Washington D.C.: National Centers for Environmental Information, National Oceanic and Atmospheric Administration.

Pierce, K. (2015). SOI migration data, a new approach: Methodological improvements for SOIC's United States population migration data, calendar years 2011-2012. Washington D.C.: Statistics of Income, Internal Revenue Service.

Poulain, M., Perrin, N., and Singleton, A. (2006). THESIM: Towards harmonized European statistics on international migration. Louvain-la-Neuve: UCL Presses Universitaires de Louvain.

Preston, S.H., Heuveline, P., and Guillot, M. (2001). Demography: Measuring and modeling population processes. Oxford: Blackwell Publishers.

Raymer, J., Willekens, F., and Rogers, A. (2018). Spatial demography: A unifying core and agenda for future research. Population, Space and Place 25(4). doi:10.1002/ psp. 2179 .

Raymer, J., Wiśniowski, A., Forster, J.J., Smith, P.W.F., and Bijak, J. (2013). Integrated modeling of European migration. Journal of the American Statistical Association 108(503): 801-819. doi:10.1080/01621459.2013.789435.

Rodríguez-Díaz, C.E. (2018). Maria in Puerto Rico: Natural disaster in a colonial archipelago. American Journal of Public Health 108(1): 30-32. doi:10.2105/ AJPH.2017.304198.

Rogers, A. (1975). Introduction to multiregional mathematical demography. New York: John Wiley and Sons. 
Rogers, A. and Castro, L.J. (1981). Model migration schedules. Laxenburg: International Institute for Applied Systems Research (IIASA Research Report RR-81-030).

Rogers, A. and Watkins, J. (1987). General versus elderly interstate migration and population redistribution in the United States. Research on Aging 9(4): 483-529. doi:10.1177/0164027587094002.

Roseman, C.C. (1971). Migration as a spatial and temporal process. Annals of the Association of American Geographers 61(3): 589-598. doi:10.1111/j.14678306.1971.tb00809.x.

Ruggles, S. (2018). Implications of differential privacy for Census Bureau data and scientific research. Minneapolis, MN: Minnesota Population Center, University of Minnesota (Working Paper 2018-6).

Tran, B.R. and Sheldon, T.L. (2018). Same storm, different disasters: Consumer credit access, income inequality, and natural disaster recovery. Paper presented at annual meeting of the American Economic Association, Philadelphia, PA, USA, January 5-7, 2018.

Whitaker, S.D. (2018). Big data versus a survey. The Quarterly Review of Economics and Finance 67: 285-296. doi:10.1016/j.qref.2017.07.011.

White, M.J. (2016). International handbook of migration and population distribution. New York: Springer.

Willekens, F., Massey, D.S., Raymer, J., and Beauchemin, C. (2016). International migration under the microscope. Science 352 (6288): 897-899. doi:10.1126/ science.aaf6545.

Wilson, T. (2010). Model migration schedules incorporating student migration peaks. Demographic Research 23(8): 191-222. doi:10.4054/DemRes.2010.23.8.

Zabel, J.E. (1998). An analysis of attrition in the Panel Study of Income Dynamics and the Survey of Income and Program Participation with an application to a model of labor market behavior. The Journal of Human Resources 33(2): 479-506. doi:10.2307/146438.

Zorrilla, C.D. (2017). The view from Puerto Rico-Hurricane Maria and its aftermath. The New England Journal of Medicine 377: 1801-1803. doi:10.1056/NEJMp 1713196. 


\section{Appendix}

Table A-1: Estimates and standard errors of annual crude migration probability of US internal migration at state, county, and tract levels since 2005 in Consumer Credit Panel, American Community Survey, and Current Population Survey

\begin{tabular}{|c|c|c|c|c|c|c|c|}
\hline & \multicolumn{3}{|c|}{ State } & \multicolumn{3}{|c|}{ County/MIGPUMA } & \multirow{2}{*}{$\begin{array}{l}\text { Tract } \\
\text { CCP }\end{array}$} \\
\hline & CCP & ACS & CPS & CCP & ACS & CPS & \\
\hline \multirow[t]{2}{*}{2005} & 0.0468 & 0.0251 & 0.0181 & 0.0946 & 0.0532 & 0.0400 & 0.1848 \\
\hline & $(0.0001)$ & $(0.0001)$ & $(0.0004)$ & $(0.0001)$ & $(0.0002)$ & $(0.0006)$ & $(0.0001)$ \\
\hline \multirow[t]{2}{*}{2006} & 0.0284 & 0.0249 & 0.0179 & 0.0609 & 0.0530 & 0.0427 & 0.1285 \\
\hline & $(0.0001)$ & $(0.0001)$ & $(0.0004)$ & $(0.0001)$ & $(0.0002)$ & $(0.0006)$ & $(0.0001)$ \\
\hline \multirow[t]{2}{*}{2007} & 0.0300 & 0.0235 & 0.0157 & 0.0636 & 0.0499 & 0.0375 & 0.1327 \\
\hline & $(0.0001)$ & $(0.0001)$ & $(0.0004)$ & $(0.0001)$ & $(0.0002)$ & $(0.0006)$ & $(0.0001)$ \\
\hline \multirow[t]{2}{*}{2008} & 0.0275 & 0.0225 & 0.0148 & 0.0588 & 0.0480 & 0.0337 & 0.1231 \\
\hline & $(0.0001)$ & $(0.0001)$ & $(0.0004)$ & $(0.0001)$ & $(0.0002)$ & $(0.0005)$ & $(0.0001)$ \\
\hline \multirow[t]{2}{*}{2009} & 0.0243 & 0.0211 & 0.0145 & 0.0510 & 0.0456 & 0.0333 & 0.1054 \\
\hline & $(0.0000)$ & $(0.0001)$ & $(0.0004)$ & $(0.0001)$ & $(0.0002)$ & $(0.0005)$ & $(0.0001)$ \\
\hline \multirow[t]{2}{*}{2010} & 0.0227 & 0.0205 & 0.0134 & 0.0480 & 0.0448 & 0.0310 & 0.1086 \\
\hline & $(0.0000)$ & $(0.0001)$ & $(0.0003)$ & $(0.0001)$ & $(0.0002)$ & $(0.0005)$ & $(0.0001)$ \\
\hline \multirow[t]{2}{*}{2011} & 0.0225 & 0.0209 & 0.0144 & 0.0473 & 0.0450 & 0.0316 & 0.1122 \\
\hline & $(0.0000)$ & $(0.0001)$ & $(0.0004)$ & $(0.0001)$ & $(0.0002)$ & $(0.0005)$ & $(0.0001)$ \\
\hline \multirow[t]{2}{*}{2012} & 0.0235 & 0.0211 & 0.0149 & 0.0494 & 0.0443 & 0.0339 & 0.1061 \\
\hline & $(0.0000)$ & $(0.0001)$ & $(0.0004)$ & $(0.0001)$ & $(0.0002)$ & $(0.0006)$ & $(0.0001)$ \\
\hline \multirow[t]{2}{*}{2013} & 0.0191 & 0.0218 & 0.0149 & 0.0415 & 0.0457 & 0.0341 & 0.0916 \\
\hline & $(0.0000)$ & $(0.0001)$ & $(0.0004)$ & $(0.0001)$ & $(0.0002)$ & $(0.0006)$ & $(0.0001)$ \\
\hline \multirow[t]{2}{*}{2014} & 0.0184 & 0.0221 & 0.0141 & 0.0411 & 0.0463 & 0.0315 & 0.0917 \\
\hline & $(0.0000)$ & $(0.0001)$ & $(0.0005)$ & $(0.0001)$ & $(0.0002)$ & $(0.0007)$ & $(0.0001)$ \\
\hline \multirow[t]{2}{*}{2015} & 0.0201 & 0.0223 & 0.0149 & 0.0475 & 0.0463 & 0.0323 & 0.0986 \\
\hline & $(0.0000)$ & $(0.0001)$ & $(0.0004)$ & $(0.0001)$ & $(0.0002)$ & $(0.0006)$ & $(0.0001)$ \\
\hline \multirow[t]{2}{*}{2016} & 0.0204 & 0.0221 & 0.0149 & 0.0451 & 0.0464 & 0.0345 & 0.0989 \\
\hline & $(0.0000)$ & $(0.0001)$ & $(0.0004)$ & $(0.0001)$ & $(0.0002)$ & $(0.0006)$ & $(0.0001)$ \\
\hline \multirow[t]{2}{*}{2017} & 0.0202 & 0.0219 & 0.0156 & 0.0448 & 0.0465 & 0.0336 & 0.1032 \\
\hline & $(0.0000)$ & $(0.0001)$ & $(0.0004)$ & $(0.0001)$ & $(0.0002)$ & $(0.0006)$ & $(0.0001)$ \\
\hline \multirow[t]{2}{*}{2018} & 0.0247 & & 0.0139 & 0.0528 & & 0.0313 & 0.1064 \\
\hline & $(0.0000)$ & & $(0.0004)$ & $(0.0001)$ & & $(0.0006)$ & $(0.0001)$ \\
\hline \multirow[t]{2}{*}{2019} & 0.0234 & & & 0.0510 & & & 0.1053 \\
\hline & $(0.0000)$ & & & $(0.0001)$ & & & $(0.0001)$ \\
\hline
\end{tabular}

Notes: Selection criteria for analysis provided in Table 1. CCP = Consumer Credit Panel; ACS = American Community Survey; CPS = Current Population Survey. Due to data limitations, county ACS estimates reflect Public Use Microdata Areas for Migration (MIGPUMAs), not counties. ACS and CPS estimates are weighted. 
Table A-2: Annual age distributions since 2005 in Consumer Credit Panel, American Community Survey, and Current Population Survey

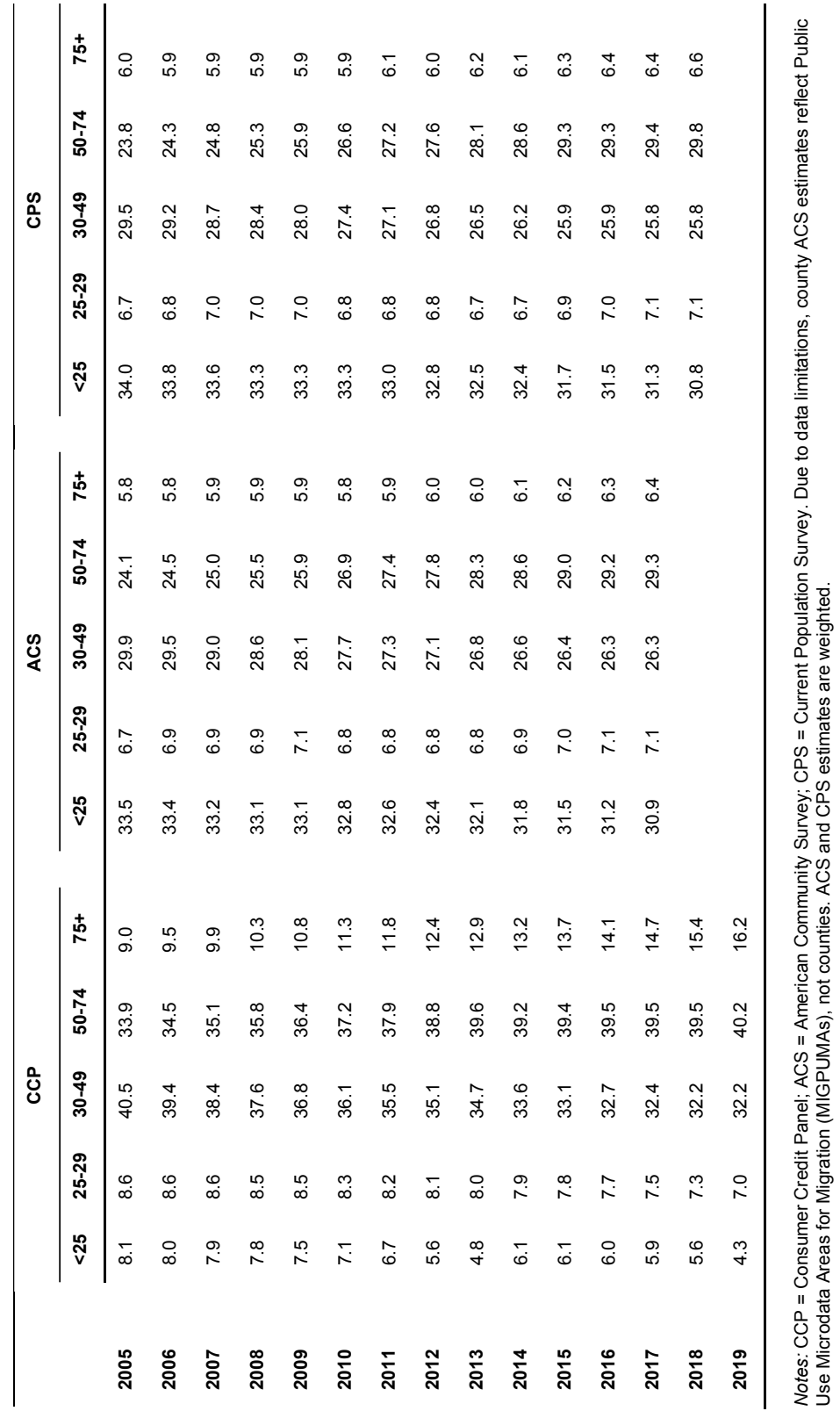


Table A-3: Estimates and standard errors of annual crude migration probability of US internal migration by age group at state, county, and tract levels since 2005 in Consumer Credit Panel, American Community Survey, and Current Population Survey

Panel A. Young adults (age 25-29)

\begin{tabular}{|c|c|c|c|c|c|c|c|}
\hline & \multicolumn{3}{|c|}{ State } & \multicolumn{3}{|c|}{ County/MIGPUMA } & \multirow{2}{*}{$\begin{array}{l}\text { Tract } \\
\text { CCP }\end{array}$} \\
\hline & CCP & ACS & CPS & CCP & ACS & CPS & \\
\hline \multirow[t]{2}{*}{2005} & 0.0830 & 0.0502 & 0.0371 & 0.1755 & 0.1106 & 0.0836 & 0.3328 \\
\hline & $(0.0003)$ & $(0.0007)$ & $(0.0024)$ & $(0.0004)$ & $(0.0010)$ & $(0.0035)$ & $(0.0005)$ \\
\hline \multirow[t]{2}{*}{2006} & 0.05670 & 0.0485 & 0.0331 & 0.1253 & 0.1094 & 0.0857 & 0.2531 \\
\hline & $(0.0002)$ & $(0.0007)$ & $(0.0021)$ & $(0.0004)$ & $(0.0010)$ & $(0.0034)$ & $(0.0005)$ \\
\hline \multirow[t]{2}{*}{2007} & 0.0617 & 0.0480 & 0.0324 & 0.1335 & 0.1069 & 0.0793 & 0.2657 \\
\hline & $(0.0003)$ & $(0.0007)$ & $(0.0021)$ & $(0.0004)$ & $(0.0010)$ & $(0.0033)$ & $(0.0005)$ \\
\hline \multirow[t]{2}{*}{2008} & 0.0592 & 0.0463 & 0.0320 & 0.1298 & 0.1033 & 0.0776 & 0.2612 \\
\hline & $(0.0002)$ & $(0.0007)$ & $(0.0021)$ & $(0.0004)$ & $(0.0010)$ & $(0.0032)$ & $(0.0005)$ \\
\hline \multirow[t]{2}{*}{2009} & 0.0527 & 0.0449 & 0.0370 & 0.1135 & 0.0988 & 0.0801 & 0.2276 \\
\hline & $(0.0002)$ & $(0.0006)$ & $(0.0022)$ & $(0.0003)$ & $(0.0009)$ & $(0.0032)$ & $(0.0004)$ \\
\hline \multirow[t]{2}{*}{2010} & 0.0498 & 0.0440 & 0.0316 & 0.1073 & 0.0979 & 0.0699 & 0.2251 \\
\hline & $(0.0002)$ & $(0.0006)$ & $(0.0020)$ & $(0.0003)$ & $(0.0009)$ & $(0.0030)$ & $(0.0004)$ \\
\hline \multirow[t]{2}{*}{2011} & 0.0520 & 0.0458 & 0.0314 & 0.1099 & 0.0975 & 0.0719 & 0.2301 \\
\hline & $(0.0002)$ & $(0.0007)$ & $(0.0021)$ & $(0.0003)$ & $(0.0010)$ & $(0.0031)$ & $(0.0004)$ \\
\hline \multirow[t]{2}{*}{2012} & 0.0551 & 0.0450 & 0.0364 & 0.1166 & 0.0946 & 0.0757 & 0.2320 \\
\hline & $(0.0002)$ & $(0.0007)$ & $(0.0023)$ & $(0.0003)$ & $(0.0009)$ & $(0.0033)$ & $(0.0004)$ \\
\hline \multirow[t]{2}{*}{2013} & 0.0447 & 0.0480 & 0.0346 & 0.0984 & 0.1009 & 0.0784 & 0.2048 \\
\hline & $(0.0002)$ & $(0.0007)$ & $(0.0022)$ & $(0.0003)$ & $(0.0009)$ & $(0.0034)$ & $(0.0004)$ \\
\hline \multirow[t]{2}{*}{2014} & 0.0443 & 0.0465 & 0.0333 & 0.0994 & 0.0982 & 0.0697 & 0.2071 \\
\hline & $(0.0002)$ & $(0.0006)$ & $(0.0029)$ & $(0.0003)$ & $(0.0009)$ & $(0.0040)$ & $(0.0004)$ \\
\hline \multirow[t]{2}{*}{2015} & 0.0484 & 0.0478 & 0.0301 & 0.1090 & 0.0999 & 0.0709 & 0.2188 \\
\hline & $(0.0002)$ & $(0.0007)$ & $(0.0021)$ & $(0.0003)$ & $(0.0009)$ & $(0.0033)$ & $(0.0004)$ \\
\hline \multirow[t]{2}{*}{2016} & 0.0482 & 0.0457 & 0.0361 & 0.1072 & 0.0988 & 0.084 & 0.2200 \\
\hline & $(0.0002)$ & $(0.0006)$ & $(0.0026)$ & $(0.0003)$ & $(0.0009)$ & $(0.0038)$ & $(0.0004)$ \\
\hline \multirow[t]{2}{*}{2017} & 0.0480 & 0.0466 & 0.0395 & 0.1067 & 0.0999 & 0.0808 & 0.2238 \\
\hline & $(0.0002)$ & $(0.0006)$ & $(0.0026)$ & $(0.0003)$ & $(0.0009)$ & $(0.0036)$ & $(0.0004)$ \\
\hline \multirow[t]{2}{*}{2018} & 0.0589 & & 0.0287 & 0.1252 & & 0.0646 & 0.2379 \\
\hline & $(0.0003)$ & & $(0.0023)$ & $(0.0004)$ & & $(0.0035)$ & $(0.0005)$ \\
\hline \multirow[t]{2}{*}{2019} & 0.0548 & & & 0.1191 & & & 0.2310 \\
\hline & $(0.0002)$ & & & $(0.0004)$ & & & $(0.0005)$ \\
\hline
\end{tabular}


DeWaard, Johnson \& Whitaker: Internal migration in the United States

Table A-3: (Continued)

Panel B. Family age (age 30-49)

\begin{tabular}{|c|c|c|c|c|c|c|c|}
\hline & \multicolumn{3}{|c|}{ State } & \multicolumn{3}{|c|}{ County/MIGPUMA } & \multirow{2}{*}{$\begin{array}{l}\text { Tract } \\
\text { CCP }\end{array}$} \\
\hline & CCP & ACS & CPS & CCP & ACS & CPS & \\
\hline \multirow[t]{2}{*}{2005} & 0.0472 & 0.0248 & 0.0181 & 0.0978 & 0.0518 & 0.0396 & 0.2032 \\
\hline & $(0.0001)$ & $(0.0002)$ & $(0.0007)$ & $(0.0001)$ & $(0.0003)$ & $(0.0011)$ & $(0.0002)$ \\
\hline \multirow[t]{2}{*}{2006} & 0.0299 & 0.0255 & 0.0192 & 0.0649 & 0.0526 & 0.0445 & 0.1444 \\
\hline & $(0.0001)$ & $(0.0002)$ & $(0.0008)$ & $(0.0001)$ & $(0.0003)$ & $(0.0012)$ & $(0.0002)$ \\
\hline \multirow[t]{2}{*}{2007} & 0.0320 & 0.0241 & 0.0161 & 0.0684 & 0.0490 & 0.0382 & 0.1505 \\
\hline & $(0.0001)$ & $(0.0002)$ & $(0.0007)$ & $(0.0001)$ & $(0.0003)$ & $(0.0011)$ & $(0.0002)$ \\
\hline \multirow[t]{2}{*}{2008} & 0.0298 & 0.0229 & 0.0154 & 0.0642 & 0.0474 & 0.0337 & 0.1415 \\
\hline & $(0.0001)$ & $(0.0002)$ & $(0.0007)$ & $(0.0001)$ & $(0.0003)$ & $(0.0010)$ & $(0.0002)$ \\
\hline \multirow[t]{2}{*}{2009} & 0.0265 & 0.0214 & 0.0153 & 0.0560 & 0.0451 & 0.0331 & 0.1220 \\
\hline & $(0.0001)$ & $(0.0002)$ & $(0.0007)$ & $(0.0001)$ & $(0.0003)$ & $(0.0010)$ & $(0.0002)$ \\
\hline \multirow[t]{2}{*}{2010} & 0.0251 & 0.0206 & 0.0134 & 0.0540 & 0.0446 & 0.0307 & 0.1278 \\
\hline & $(0.0001)$ & $(0.0002)$ & $(0.0006)$ & $(0.0001)$ & $(0.0003)$ & $(0.0010)$ & $(0.0002)$ \\
\hline \multirow[t]{2}{*}{2011} & 0.0261 & 0.0220 & 0.0155 & 0.0557 & 0.0463 & 0.0321 & 0.1352 \\
\hline & $(0.0001)$ & $(0.0002)$ & $(0.0007)$ & $(0.0001)$ & $(0.0003)$ & $(0.0011)$ & $(0.0002)$ \\
\hline \multirow[t]{2}{*}{2012} & 0.0279 & 0.0222 & 0.0157 & 0.0594 & 0.0457 & 0.0353 & 0.1332 \\
\hline & $(0.0001)$ & $(0.0002)$ & $(0.0007)$ & $(0.0001)$ & $(0.0003)$ & $(0.0011)$ & $(0.0002)$ \\
\hline \multirow[t]{2}{*}{2013} & 0.0232 & 0.0226 & 0.0165 & 0.0512 & 0.0467 & 0.0369 & 0.1187 \\
\hline & $(0.0001)$ & $(0.0002)$ & $(0.0007)$ & $(0.0001)$ & $(0.0003)$ & $(0.0011)$ & $(0.0002)$ \\
\hline \multirow[t]{2}{*}{2014} & 0.0236 & 0.0235 & 0.0147 & 0.0534 & 0.0481 & 0.0329 & 0.1233 \\
\hline & $(0.0001)$ & $(0.0002)$ & $(0.0009)$ & $(0.0001)$ & $(0.0003)$ & $(0.0013)$ & $(0.0002)$ \\
\hline \multirow[t]{2}{*}{2015} & 0.0266 & 0.0238 & 0.0179 & 0.0619 & 0.0485 & 0.0358 & 0.1343 \\
\hline & $(0.0001)$ & $(0.0002)$ & $(0.0009)$ & $(0.0001)$ & $(0.0003)$ & $(0.0012)$ & $(0.0002)$ \\
\hline \multirow[t]{2}{*}{2016} & 0.0271 & 0.0237 & 0.017 & 0.0604 & 0.0486 & 0.0373 & 0.1367 \\
\hline & $(0.0001)$ & $(0.0002)$ & $(0.0009)$ & $(0.0001)$ & $(0.0003)$ & $(0.0012)$ & $(0.0002)$ \\
\hline \multirow[t]{2}{*}{2017} & 0.0271 & 0.0236 & 0.0176 & 0.0606 & 0.0495 & 0.0367 & 0.1416 \\
\hline & $(0.0001)$ & $(0.0002)$ & $(0.0008)$ & $(0.0001)$ & $(0.0003)$ & $(0.0012)$ & $(0.0002)$ \\
\hline \multirow[t]{2}{*}{2018} & 0.0331 & & 0.0147 & 0.0715 & & 0.0338 & 0.1491 \\
\hline & $(0.0001)$ & & $(0.0008)$ & $(0.0001)$ & & $(0.0012)$ & $(0.0002)$ \\
\hline \multirow[t]{2}{*}{2019} & 0.0313 & & & 0.0693 & & & 0.1482 \\
\hline & $(0.0001)$ & & & $(0.0001)$ & & & $(0.0002)$ \\
\hline
\end{tabular}


Table A-3: (Continued)

Panel C. Older adults (age 50-74)

\begin{tabular}{|c|c|c|c|c|c|c|c|}
\hline & \multicolumn{3}{|c|}{ State } & \multicolumn{3}{|c|}{ County/MIGPUMA } & \multirow{2}{*}{$\begin{array}{l}\text { Tract } \\
\text { CCPP }\end{array}$} \\
\hline & CCP & ACS & CPS & CCP & ACS & CPS & \\
\hline \multirow[t]{2}{*}{2005} & 0.0373 & 0.0150 & 0.0099 & 0.0705 & 0.0286 & 0.0190 & 0.1321 \\
\hline & $(0.0001)$ & $(0.0002)$ & $(0.0006)$ & $(0.0001)$ & $(0.0003)$ & $(0.0009)$ & $(0.0002)$ \\
\hline \multirow[t]{2}{*}{2006} & 0.0195 & 0.0149 & 0.0086 & 0.0399 & 0.0286 & 0.0194 & 0.0834 \\
\hline & $(0.0001)$ & $(0.0002)$ & $(0.0006)$ & $(0.0001)$ & $(0.0002)$ & $(0.0009)$ & $(0.0001)$ \\
\hline \multirow[t]{2}{*}{2007} & 0.0202 & 0.0134 & 0.0081 & 0.0414 & 0.0260 & 0.0175 & 0.0863 \\
\hline & $(0.0001)$ & $(0.0002)$ & $(0.0005)$ & $(0.0001)$ & $(0.0002)$ & $(0.0008)$ & $(0.0001)$ \\
\hline \multirow[t]{2}{*}{2008} & 0.0177 & 0.0124 & 0.0074 & 0.0364 & 0.0243 & 0.0160 & 0.0754 \\
\hline & $(0.0001)$ & $(0.0002)$ & $(0.0005)$ & $(0.0001)$ & $(0.0002)$ & $(0.0008)$ & $(0.0001)$ \\
\hline \multirow[t]{2}{*}{2009} & 0.0157 & 0.0115 & 0.0064 & 0.0318 & 0.0229 & 0.0138 & 0.0652 \\
\hline & $(0.0001)$ & $(0.0001)$ & $(0.0005)$ & $(0.0001)$ & $(0.0002)$ & $(0.0007)$ & $(0.0001)$ \\
\hline \multirow[t]{2}{*}{2010} & 0.0150 & 0.0122 & 0.0070 & 0.0310 & 0.0235 & 0.0150 & 0.0723 \\
\hline & $(0.0001)$ & $(0.0001)$ & $(0.0005)$ & $(0.0001)$ & $(0.0002)$ & $(0.0007)$ & $(0.0001)$ \\
\hline \multirow[t]{2}{*}{2011} & 0.0144 & 0.0123 & 0.0071 & 0.0296 & 0.0244 & 0.0143 & 0.0760 \\
\hline & $(0.0001)$ & $(0.0002)$ & $(0.0005)$ & $(0.0001)$ & $(0.0002)$ & $(0.0007)$ & $(0.0001)$ \\
\hline \multirow[t]{2}{*}{2012} & 0.0148 & 0.0125 & 0.0069 & 0.0303 & 0.0243 & 0.0157 & 0.0672 \\
\hline & $(0.0001)$ & $(0.0002)$ & $(0.0005)$ & $(0.0001)$ & $(0.0002)$ & $(0.0008)$ & $(0.0001)$ \\
\hline \multirow[t]{2}{*}{2013} & 0.0121 & 0.0128 & 0.0072 & 0.0258 & 0.0253 & 0.0155 & 0.0570 \\
\hline & $(0.0001)$ & $(0.0002)$ & $(0.0005)$ & $(0.0001)$ & $(0.0002)$ & $(0.0007)$ & $(0.0001)$ \\
\hline \multirow[t]{2}{*}{2014} & 0.0118 & 0.0132 & 0.0079 & 0.0256 & 0.0258 & 0.0164 & 0.0577 \\
\hline & $(0.0001)$ & $(0.0002)$ & $(0.0006)$ & $(0.0001)$ & $(0.0002)$ & $(0.0009)$ & $(0.0001)$ \\
\hline \multirow[t]{2}{*}{2015} & 0.0126 & 0.0137 & 0.0076 & 0.0310 & 0.0266 & 0.0161 & 0.0625 \\
\hline & $(0.0001)$ & $(0.0002)$ & $(0.0005)$ & $(0.0001)$ & $(0.0002)$ & $(0.0007)$ & $(0.0001)$ \\
\hline \multirow[t]{2}{*}{2016} & 0.0133 & 0.0137 & 0.0072 & 0.0286 & 0.0269 & 0.0156 & 0.0630 \\
\hline & $(0.0001)$ & $(0.0002)$ & $(0.0005)$ & $(0.0001)$ & $(0.0002)$ & $(0.0008)$ & $(0.0001)$ \\
\hline \multirow[t]{2}{*}{2017} & 0.0133 & 0.0135 & 0.0075 & 0.0287 & 0.0272 & 0.0159 & 0.0679 \\
\hline & $(0.0001)$ & $(0.0002)$ & $(0.0005)$ & $(0.0001)$ & $(0.0002)$ & $(0.0008)$ & $(0.0001)$ \\
\hline \multirow[t]{2}{*}{2018} & 0.0165 & & 0.0073 & 0.0344 & & 0.0175 & 0.0692 \\
\hline & $(0.0001)$ & & $(0.0006)$ & $(0.0001)$ & & $(0.0009)$ & $(0.0001)$ \\
\hline \multirow[t]{2}{*}{2019} & 0.0161 & & & 0.0342 & & & 0.0709 \\
\hline & $(0.0001)$ & & & $(0.0001)$ & & & $(0.0001)$ \\
\hline
\end{tabular}

Notes: Selection criteria for analysis provided in Table 1. CCP = Consumer Credit Panel; ACS = American Community Survey; $\mathrm{CPS}=$ Current Population Survey. Due to data limitations, county ACS estimates reflect Public Use Microdata Areas for Migration (MIGPUMAs), not counties. ACS and CPS estimates are weighted. 
Table A-4: Estimates and standard errors of migration progression ratio of first US internal migration at state, county, and tract levels in Consumer Credit Panel, National Longitudinal Survey of Youth (1979 and 1997 cohorts), Panel Study of Income Dynamics, and Survey of Income and Program Participation (2004 and 2008)

\begin{tabular}{|c|c|c|c|}
\hline & State & County & Tract \\
\hline \multirow[t]{2}{*}{ NLSY79 } & 0.1090 & 0.2470 & \\
\hline & $(0.0050)$ & $(0.0070)$ & \\
\hline \multirow[t]{2}{*}{ CCP-Equivalent } & 0.1266 & 0.2563 & \\
\hline & $(0.0002)$ & $(0.0003)$ & \\
\hline \multirow[t]{2}{*}{ NLSY97 } & 0.3220 & 0.6180 & \\
\hline & $(0.0080)$ & $(0.0080)$ & \\
\hline \multirow[t]{2}{*}{ CCP-Equivalent } & 0.3085 & 0.5838 & \\
\hline & $(0.0005)$ & $(0.0006)$ & \\
\hline \multirow[t]{2}{*}{ PSID } & 0.1640 & & \\
\hline & $(0.0030)$ & & \\
\hline \multirow[t]{2}{*}{ CCP-Equivalent } & 0.1377 & & \\
\hline & $(0.0001)$ & & \\
\hline \multirow[t]{2}{*}{ SIPP04 } & 0.0420 & & \\
\hline & $(0.0010)$ & & \\
\hline \multirow[t]{2}{*}{ CCP-Equivalent } & 0.0932 & & \\
\hline & $(0.0001)$ & & \\
\hline \multirow[t]{2}{*}{ SIPP08 } & 0.0480 & & \\
\hline & $(0.0002)$ & & \\
\hline \multirow[t]{2}{*}{ CCP-Equivalent } & 0.0905 & & \\
\hline & $(0.0001)$ & & \\
\hline \multirow[t]{2}{*}{$\mathrm{CCP}$} & 0.2234 & 0.4196 & 0.6805 \\
\hline & $(0.0001)$ & $(0.0001)$ & $(0.0001)$ \\
\hline
\end{tabular}

Notes: Selection criteria for analysis provided in Table 4. CCP = Consumer Credit Panel; NLSY79 = National Longitudinal Survey of Youth, 1979 Cohort; NLSY97 = National Longitudinal Survey of Youth, 1997 Cohort; PSID = Panel Study of Income Dynamics; SIPP04 = Survey of Income and Program Participation 2004; SIPP08 = Survey of Income and Program Participation 2008. CCP sample contains all individuals with complete panels from Q1 2005 to Q1 2015; locations are derived from current mailing addresses reported by lenders to Equifax. NLSY79 sample contains all individuals age 39-47 as of January 2004 with nonmissing migration information through 2014 interview; location measured as of biennial interview date from January 2004-December 2014. NLSY97 sample contains all individuals age $20-24$ as of January 2004 with nonmissing migration information through 2016 interview; location measured as of biennial interview date from January 2004-June 2016. PSID observation period spans 2005-2015; location measured biennially. SIPP04 observation period spans March 2004-March 2007; location measured quarterly. SIPP08 observation period spans September 2008-September 2013; location measured quarterly. 
Table A-5: Estimates and standard errors of migration progression ratio of first US internal migration by age group at state, county, and tract levels in the Consumer Credit Panel, Panel Study of Income Dynamics, and Survey of Income and Program Participation (2004 and 2008)

Panel A. Young adults (age 25-29)

\begin{tabular}{lccc}
\hline & State & County & Tract \\
\hline PSID & 0.1945 & & \\
CCP-Equivalent & $(0.0142)$ & & \\
& 0.2349 & & \\
SIPP04 & $(0.0005)$ & & \\
& 0.0995 & & \\
CCP-Equivalent & $(0.0099)$ & & \\
& 0.1664 & & \\
SIPP08 & $(0.0004)$ & & \\
& & & \\
CCP-Equivalent & 0.1117 & & \\
& $(0.0134)$ & 0.8086 \\
& 0.1403 & $0.0003)$ \\
\hline
\end{tabular}

Panel B. Family age adults (age 30-49)

\begin{tabular}{lccc}
\hline & State & County & Tract \\
\hline PSID & 0.1241 & & \\
CCP-Equivalent & $(0.0068)$ & & \\
& 0.1348 & & \\
SIPP04 & $(0.0002)$ & & \\
& & & \\
CCP-Equivalent & 0.0440 & & \\
& $(0.0027)$ & & \\
SIPP08 & 0.0913 & & \\
& $(0.0001)$ & & \\
CCP-Equivalent & 0.0645 & & 0.6944 \\
& $(0.0045)$ & & \\
& 0.0767 & $0.0002)$ \\
\hline
\end{tabular}


Table A-5: (Continued)

Panel C. Older adults (age 50-74)

\begin{tabular}{|c|c|c|c|}
\hline & State & County & Tract \\
\hline \multirow[t]{2}{*}{ PSID } & 0.0905 & & \\
\hline & $(0.007)$ & & \\
\hline \multirow[t]{2}{*}{ CCP-Equivalent } & 0.977 & & \\
\hline & $(0.0002)$ & & \\
\hline \multirow[t]{2}{*}{ SIPP04 } & 0.0255 & & \\
\hline & $(0.0020)$ & & \\
\hline \multirow[t]{2}{*}{ CCP-Equivalent } & 0.0699 & & \\
\hline & $(0.0001)$ & & \\
\hline \multirow[t]{2}{*}{ SIPP08 } & 0.0287 & & \\
\hline & $(0.0024)$ & & \\
\hline \multirow[t]{2}{*}{ CCP-Equivalent } & 0.0603 & & \\
\hline & $(0.0001)$ & & \\
\hline \multirow[t]{2}{*}{ CCP } & 0.1734 & 0.3186 & 0.5554 \\
\hline & $(0.0002)$ & $(0.0003)$ & $(0.0003)$ \\
\hline
\end{tabular}

Notes: Selection criteria for analysis provided in Table 4. CCP = Consumer Credit Panel; PSID = Panel Study of Income Dynamics; SIPP04 = Survey of Income and Program Participation 2004; SIPP08 = Survey of Income and Program Participation 2008. CCP sample contains all individuals with complete panels from Q1 2005 to Q1 2015. Locations are derived from current mailing addresses reported by lenders to Equifax. PSID observation period spans 2005-2015; location measured biennially. SIPP04 observation period spans March 2004-March 2007; location measured quarterly. SIPP08 observation period spans September 2008-September 2013; location measured quarterly. 
Table A-6: Estimates and standard errors of migration progression ratios of second and third US internal migration at state, county, and tract levels in Consumer Credit Panel, National Longitudinal Survey of Youth (1979 and 1997 cohorts), Panel Study of Income Dynamics, and Survey of Income and Program Participation (2004 and 2008)

Panel A. Second migration

\begin{tabular}{|c|c|c|c|}
\hline & State & County & Tract \\
\hline \multirow[t]{2}{*}{ NLSY79 } & 0.3210 & 0.4070 & \\
\hline & $(0.0220)$ & $(0.0150)$ & \\
\hline \multirow[t]{2}{*}{ CCP-Equivalent } & 0.2694 & 0.3230 & \\
\hline & $(0.0009)$ & $(0.0007)$ & \\
\hline \multirow[t]{2}{*}{ NLSY97 } & 0.5600 & 0.6900 & \\
\hline & $(0.0160)$ & $(0.0100)$ & \\
\hline \multirow[t]{2}{*}{ CCP-Equivalent } & 0.5099 & 0.6027 & \\
\hline & $(0.0011)$ & $(0.0008)$ & \\
\hline \multirow[t]{2}{*}{ PSID } & 0.3800 & & \\
\hline & $(0.0100)$ & & \\
\hline \multirow[t]{2}{*}{ CCP-Equivalent } & 0.3130 & & \\
\hline & $(0.0004)$ & & \\
\hline \multirow[t]{2}{*}{ SIPP04 } & 0.1990 & & \\
\hline & $(0.0140)$ & & \\
\hline \multirow[t]{2}{*}{ CCP-Equivalent } & 0.2809 & & \\
\hline & $(0.0005)$ & & \\
\hline \multirow[t]{2}{*}{ SIPP08 } & 0.2400 & & \\
\hline & $(0.0190)$ & & \\
\hline \multirow[t]{2}{*}{ CCP-Equivalent } & 0.3608 & & \\
\hline & $(0.0005)$ & & \\
\hline \multirow[t]{2}{*}{ CCP } & 0.4948 & 0.5649 & 0.6840 \\
\hline & $(0.0003)$ & $(0.0002)$ & $(0.0002)$ \\
\hline
\end{tabular}




\section{Table A-6: (Continued)}

\section{Panel B. Third migration}

\begin{tabular}{|c|c|c|c|}
\hline & State & County & Tract \\
\hline \multirow[t]{2}{*}{ NLSY79 } & 0.2150 & 0.2960 & \\
\hline & $(0.0033)$ & $(0.0220)$ & \\
\hline \multirow[t]{2}{*}{ CCP-Equivalent } & 0.2174 & 0.2632 & \\
\hline & $(0.0016)$ & $(0.0011)$ & \\
\hline \multirow[t]{2}{*}{ NLSY97 } & 0.4040 & 0.5820 & \\
\hline & $(0.0210)$ & $(0.0130)$ & \\
\hline \multirow[t]{2}{*}{ CCP-Equivalent } & 0.3900 & 0.5005 & \\
\hline & $(0.0015)$ & $(0.0010)$ & \\
\hline \multirow[t]{2}{*}{ PSID } & 0.2220 & & \\
\hline & $(0.0140)$ & & \\
\hline \multirow[t]{2}{*}{ CCP-Equivalent } & 0.2438 & & \\
\hline & $(0.0007)$ & & \\
\hline \multirow[t]{2}{*}{ SIPP04 } & 0.2610 & & \\
\hline & $(0.0360)$ & & \\
\hline \multirow[t]{2}{*}{ CCP-Equivalent } & 0.3928 & & \\
\hline & $(0.0010)$ & & \\
\hline \multirow[t]{2}{*}{ SIPP08 } & 0.1730 & & \\
\hline & $(0.0340)$ & & \\
\hline \multirow[t]{2}{*}{ CCP-Equivalent } & 0.4254 & & \\
\hline & $(0.0010)$ & & \\
\hline \multirow[t]{2}{*}{ CCP } & 0.4380 & 0.5311 & 0.6625 \\
\hline & $(0.0004)$ & $(0.0003)$ & $(0.0002)$ \\
\hline
\end{tabular}

Notes: Selection criteria for analysis provided in Table 4. CCP $=$ Consumer Credit Panel; NLSY79 $=$ National Longitudinal Survey of Youth, 1979 Cohort; NLSY97 = National Longitudinal Survey of Youth, 1997 Cohort; PSID = Panel Study of Income Dynamics; SIPP04 = Survey of Income and Program Participation 2004; SIPP08 = Survey of Income and Program Participation 2008. CCP sample contains all individuals with complete panels from Q1 2005 to Q1 2015. Locations are derived from current mailing addresses reported by lenders to Equifax. NLSY79 sample contains all individuals age 39-47 as of January 2004 with nonmissing migration information through 2014 interview; location measured as of biennial interview date from January 2004-December 2014. NLSY97 sample contains all individuals age 20-24 as of January 2004 with nonmissing migration information through 2016 interview; location measured as of biennial interview date from January 2004-June 2016. PSID observation period spans 2005-2015; location measured biennially. SIPP04 observation period spans March 2004-March 2007; location measured quarterly. SIPP08 observation period spans September 2008-September 2013; location measured quarterly. 


\section{Table A-7: Estimates and standard errors of return migration ratio of US internal migration at state, county, and tract levels in Consumer Credit Panel, National Longitudinal Survey of Youth (1979 and 1997 cohorts), and Panel Study of Income Dynamics}

\begin{tabular}{|c|c|c|c|}
\hline & State & County & Tract \\
\hline \multirow[t]{2}{*}{ NLSY79 } & 0.1590 & 0.1510 & \\
\hline & $(0.0170)$ & $(0.0110)$ & \\
\hline \multirow[t]{2}{*}{ CCP-Equivalent } & 0.1330 & 0.1139 & \\
\hline & $(0.0007)$ & $(0.0005)$ & \\
\hline \multirow[t]{2}{*}{ NLSY97 } & 0.2670 & 0.2140 & \\
\hline & $(0.0140)$ & $(0.0009)$ & \\
\hline \multirow[t]{2}{*}{ CCP-Equivalent } & 0.2285 & 0.1692 & \\
\hline & $(0.0009)$ & $(0.0006)$ & \\
\hline \multirow[t]{2}{*}{ PSID } & 0.2040 & & \\
\hline & $(0.0008)$ & & \\
\hline \multirow[t]{2}{*}{ CCP-Equivalent } & 0.1511 & & \\
\hline & $(0.0003)$ & & \\
\hline \multirow[t]{2}{*}{ CCP } & 0.2358 & 0.1805 & 0.0852 \\
\hline & $(0.0002)$ & $(0.0002)$ & $(0.0001)$ \\
\hline
\end{tabular}

Notes: Selection criteria for analysis provided in Table 4. CCP = Consumer Credit Panel; NLSY79 $=$ National Longitudinal Survey of Youth, 1979 Cohort; NLSY97 = National Longitudinal Survey of Youth, 1997 Cohort; PSID = Panel Study of Income Dynamics. CCP sample contains all individuals with complete panels from Q1 2005 to Q1 2015. Locations are derived from current mailing addresses reported by lenders to Equifax. NLSY79 sample contains all individuals age 39-47 as of January 2004 with nonmissing migration information through 2014 interview; location measured as of biennial interview date from January 2004-December 2014. NLSY97 sample contains all individuals age 20-24 as of January 2004 with nonmissing migration information through 2016 interview; location measured as of biennial interview date from January 2004-June 2016. PSID observation period spans 2005-2015; location measured biennially. SIPP04 observation period spans March 2004-March 2007; location measured quarterly. SIPP08 observation period spans September 2008-September 2013; location measured quarterly. 
Figure A-1: Annual crude migration probability of US internal migration at state, county, and tract levels in Consumer Credit Panel: Full series

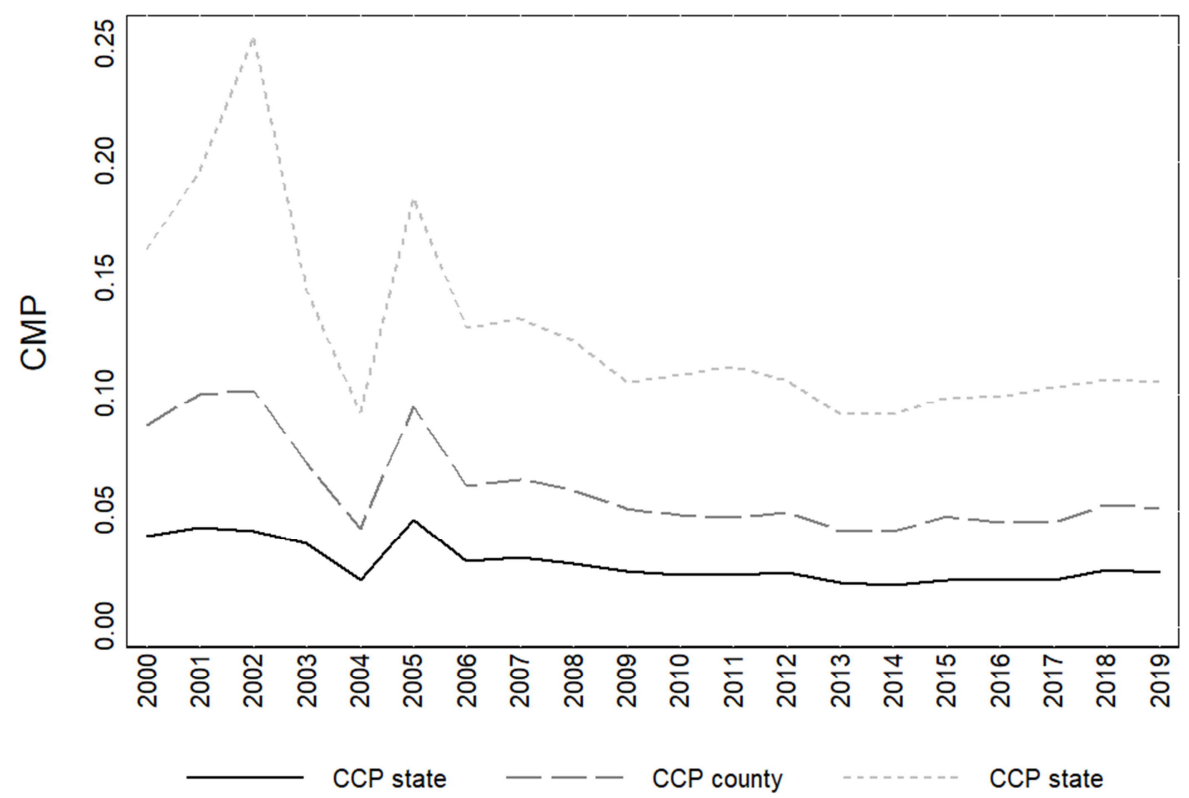

Notes: Selection criteria for analysis provided in Table 1. CMP = Crude Migration Probability. 